Illinois State University

ISU ReD: Research and eData

Theses and Dissertations

5-13-2019

\title{
When Inexpressible Becomes Expressible: The Duality Of Narrative In Graphic Memoirs Of Growing Up And Trauma
}

Nina Hanee Jang

Illinois State University, hopelander12@gmail.com

Follow this and additional works at: https://ir.library.illinoisstate.edu/etd

Part of the English Language and Literature Commons

\section{Recommended Citation}

Jang, Nina Hanee, "When Inexpressible Becomes Expressible: The Duality Of Narrative In Graphic Memoirs Of Growing Up And Trauma" (2019). Theses and Dissertations. 1129.

https://ir.library.illinoisstate.edu/etd/1129

This Thesis is brought to you for free and open access by ISU ReD: Research and eData. It has been accepted for inclusion in Theses and Dissertations by an authorized administrator of ISU ReD: Research and eData. For more information, please contact ISUReD@ilstu.edu. 


\section{WHEN INEXPRESSIBLE BECOMES EXPRESSIBLE: THE DUALITY OF NARRATIVE IN GRAPHIC MEMOIRS OF GROWING UP AND TRAUMA}

\section{NINA HANEE JANG}

\section{2 pages}

This thesis examines two graphic memoirs: Lynda Barry’s One Hundred Demons (2002), and David Small's Stitches (2009) to elucidate the connections between the duality of narrative in graphic memoirs and the subject of childhood trauma. I begin by observing how the inexpressible memories of childhood trauma become expressible through the platform of graphic narrative that allows the authors to illustrate rather than verbalize the memories. Following this analysis, I examine the aspects of embodiment and materiality in the two memoirs demonstrating how the form of graphic narrative enables the authors to effectively bring back their memories and become the witnesses of their own traumas. Finally, I explore the conventions of sequential art explaining how the traumatic memories of the past get fragmented and fictionalized and connecting it to the ethics of life narrative.

KEYWORDS: Lynda Barry, David Small, graphic narrative, comics, trauma, life writing, life narrative, autobiography, childhood, adolescence 
WHEN INEXPRESSIBLE BECOMES EXPRESSIBLE: THE DUALITY OF NARRATIVE IN GRAPHIC MEMOIRS OF GROWING UP AND TRAUMA

NINA HANEE JANG

A Thesis Submitted in Partial Fulfilment of the Requirements for the Degree of

MASTER OF ARTS

Department of English

ILLINOIS STATE UNIVERSITY

2019 
(C) 2019 Nina Hanee Jang 
WHEN INEXPRESSIBLE BECOMES EXPRESSIBLE: THE DUALITY OF NARRATIVE IN GRAPHIC MEMOIRS OF GROWING UP AND TRAUMA

NINA HANEE JANG

COMMITTEE MEMBERS:

Jan Susina, Chair

Cynthia Huff 


\section{ACKNOWLEDGMENTS}

I would like to first thank my advisor, Dr. Jan Susina, for his unending inspiration and advice he has given me throughout not only the production of this thesis but also my years in ISU as a graduate student. His genuine enthusiasm in children's literature will continue to inspire me in the rest of my academic career. Dr. Susina's devotion to his work has always motivated me to become a scholar who retain the wonder and passion of a beginner as one acquires the skills and knowledge of an expert. I would also like to thank Dr. Cynthia Huff with my genuinely grateful heart. I had the honor of working with Dr. Huff through her last year at ISU and I will never forget what it means to witness other people's life stories and tell the stories of my own through writing. Dr. Huff shaped me into a life writer that I am today, and I am forever indebted to her for supporting me to summon my own demons of my life and watch them transform into stories that touch other people’s hearts. I will continue to write my life stories and, Dr. Huff, your supportive voice will always resonate in my heart during the moments of my selfdoubt.

I would also like to thank Dr. Mary Moran and Dr. Karen Coats. They were not in my committee, but I would not have been where I am today without their consistent care and support that helped me throughout my years at ISU as a master’s student.

My thesis is much about the subject of family. Thus, I would like to now express my gratitude to my family that I was born into in South Korea. We have been through many different chapters of our story, and I am happy that our recent chapters have been much about love. Also, thank you to the family I chose here at ISU: Ann Borow, Grace Chipperfield, Heather Sanford, Shane Combs, Thelma Trujillo, and Zeph Webster. Wherever I am, it is certainly amazing and 
humbling to feel belonged. Because you made me feel belonged, I get to be who I am: a happy, positive, grateful, inquisitive, and caring person that I strive to be every day and I am forever indebted to you to make me want to be a good person. And last, but certainly not least, thank you to Gregory Crask who shows up to my life everyday no matter what, and fills my life with laughter and love.

N. H. J. 


\section{CONTENTS}

ACKNOWLEDGMENTS

$\begin{array}{lr}\text { INTRODUCTION } & 1\end{array}$

CHAPTER I: REPRESENTATION OF TRAUMA IN DUALITY

Silent Cries: The Visual Representation of Pain $\quad 5$

“The Thing Itself”: Visual Metaphors of the Inexpressible 10

CHAPTER II: BODIES, MATERIALS, AND WITNESSING: THE EMBODIED AND

$\begin{array}{ll}\text { MATERIALIZED SUBJECTS OF TRAUMA } & 16\end{array}$

$\begin{array}{ll}\text { Embodied Subjects and Becoming a Witness } & 16\end{array}$

$\begin{array}{ll}\text { The Stories of Bodies } & 18\end{array}$

$\begin{array}{ll}\text { Memory and Materiality } & 22\end{array}$

Demons, Materials of Childhood, and Therapeutic Writings of Trauma 25

Art as a Therapy: The Healing Effect of Graphic Memoirs of Trauma 31

CHAPTER III: CIRCLING BACK TO THE PAST: FRAGMENTED TIME, AND THE

$\begin{array}{ll}\text { ETHICS OF LIFE NARRATIVES } & 34\end{array}$

Frame, Gutters, and Time $\quad 34$

The Shape of Trauma $\quad 36$

Narratives of Childhood Trauma and the Fallacy of Memories $\quad 47$

Fictionality and the Ethics of Life Narrative $\quad 52$

$\begin{array}{ll}\text { CONCLUSION: CROSSING BOUNDARIES } & 61\end{array}$

$\begin{array}{lr}\text { WORKS CITED } & 70\end{array}$ 


\section{INTRODUCTION}

Graphic narrative is a term Hillary Chute uses to refer to "a book-length work composed in the medium of comics” (3). However, the lines between the terms, comics, cartoon, graphic novel, and graphic memoir often overlap and constantly cross boundaries as the field of comics and graphic narrative expanded over the last few decades influencing heavily on popular culture, academic areas and education fields. With extremely talented and artistic authors and illustrators bringing socio-politically complex subjects in book-length works such as Art Spiegelman’s Maus (1980), Alan Moore’s V for Vendetta (1988), Marjane Satrapi’s Persepolis (2000), and Alison Bechdel's Fun Home (2006), the genre of graphic narrative has gained a profound critical and scholarly attention over the last few decades by the works of leading scholars in comics studies such as Hillary Chute, Jared Gardner, Nick Sousanis, and Susan E. Kirtley. There have been many critical works that discuss the topic of comics and graphic narrative in depth and with complexity, but analyses on how the dual narrative of words and images directly connects to and play a role in the life narratives that deal with trauma and memory still require additional scholarly attention.

In "When Inexpressible Becomes Expressible: The Duality of Narrative in Graphic Memoirs of Growing up and Trauma,” I examine two graphic memoirs in particular: Lynda Barry’s One Hundred Demons (2002) and David Small’s Stitches (2009). Both authors trace the history of their trauma(s) they experienced in their childhood and adolescence and showcase how the issues they investigate evolve through the years of growing up and becoming artists as adults. In many ways, these two graphic memoirs share a common narrative pattern that allows them to be considered as nonfiction bildungsromans where a protagonist develops into an independent 
individual, as well as künstlerroman where a protagonist becomes an artist. Through vastly different narratives that share core subjects and motifs, both artists suggest artmaking as a solution to progress trauma for the dual narrative can help the artists to narrate their inexpressibly painful memories in an effective/affective way and lead them to the paths of healing. In the following three chapters, I examine how the duality of graphic narrative plays a key role in telling the stories of childhood traumas with the examples of Barry and Small's graphic memoirs.

Chapter 1 explores the ways in which the two authors utilize the duality of graphic narrative to express the inexpressible memories of their childhood trauma. Considering the critical works of scholars on comics, I will examine how Barry and Small utilize two distinctive visual tactics. First, the two authors utilize "silence" to effectively illustrate the memories of trauma that are too complex and emotionally painful to express only with words. By intentionally omitting words that describe traumatic memories and visually representing the pain and trauma, the authors are able to express the "inexpressible" memories of their childhood and adolescence. Furthermore, Barry and Small also present visual metaphors that also speak for them when they recount the memories of trauma. Considering the concepts of Nick Sousanis in Unflattening (2015), I examine how the two authors are able to visualize the trauma; the "thing itself"; through visual metaphors that closely delivers their recounting of memories instead of speaking about the traumatic events with a single rhetorical vehicle.

Chapter 2 will explain how the duality of narrative enables the authors to become not only the victims of their traumas but also the witnesses of the recounted memories of trauma through the embodiment and materiality that the medium of graphic narrative provides. While the authors tell the stories of their growing up, they present various images of their ever-evolving 
bodies. Specifically looking at the example of Small's graphic memoir which distinctly centers around the physical trauma and changes that he experienced, I argue that the narrative uniquely positions the child/adolescent protagonist and the adult narrator in an interactive space where the changing bodies of temporality are embodied along with evolving perspectives of trauma and memory are presented through the medium of graphic narrative. Furthermore, I examine how materiality makes an integral contribution in narrating the stories of one's traumatic memories of childhood and adolescence. For this task, I primarily use Barry's graphic memoir that utilize the materialities of childhood and adolescence ephemera. This analysis will also utilize Perry Nodelman's concepts in Words About Pictures: The Narrative Art of Children's Picture Books (1988) for Barry’s graphic memoir is framed in the format that can be best analyzed by understanding the functions of children's picture books. By using the ephemera of childhood and adolescence, Barry effectively/affectively brings back the memories of her growing up while allowing the readers to follow the same task with private reading experience. With embodiment and materiality that the authors benefit from the graphic narrative, artmaking becomes a healing medium for the authors who suffer from childhood traumas.

Chapter 3 examines the subjects of time and the ethics of life writing in Barry and Small's graphic memoirs. Borrowing Scott McCloud's notions in Understanding Comics: The Invisible Art (1993), I explore the conventions of sequential art such as frame, gutter, and closure, and explain how the traumatic memories of the past get fragmented and fictionalized through this fluid platform that integrates these innovative conventions. Since the format of graphic narrative allows the authors to not only narrate their stories with words but also represent them with images, the narrators can move freely from one memory from another, juxtaposing pieces of memories together and representing the shape of trauma that involves flashbacks and 
obsessive recounting of memories. Moreover, the fluidity in the form of graphic narrative raises significant questions in the ethics of life narrative. Utilizing the format of sequential art, Barry and Small break the boundaries between fiction and nonfiction and challenge the concept of one "static" truth. Rather, truth is fluid, flexible, multi-faceted, and evolving as their narratives demonstrate.

Finally, in conclusion, I synthesize my arguments from the previous chapters and frame Barry and Small's graphic memoirs as nonfiction-bildungsroman and künstlerroman that innovatively cross the boundaries of rhetorics, readerships, and genres. 


\section{CHAPTER I: REPRESENTATION OF TRAUMA IN DUALITY}

\section{Silent Cries: The Visual Representation of Pain}

The graphic memoirs of Lynda Barry and David Small seem vastly different on the surface. Barry utilizes various materialities in her graphic memoir so that Susan E. Kirtley called her artistic approach "scrapbooking the self” (148). This metaphorical analysis is most accurate considering that each material Barry uses is the sensory marker that allows her to visually recollect her memories and mediates the storytelling of her life. Barry’s seemingly cheerful scrapbook-style artworks evoke a sense of innocence and nostalgia of childhood, but underneath the masks of whimsical colors and shapes, her memories are filled with difficult subjects. On the contrary, Small adopts a remarkably different artistic style in visually representing his adolescence and trauma. He mainly uses black and white sketches and watercolor illustrations with dramatic, uneven, and jagged lines that amplify the horrors and hostilities he experienced in his youth.

Even though the two artists present very different artistic styles, they both focus on common subjects: trauma, childhood, and adolescence. In Small's case, his memories center around his cancer diagnosis and losing parts of his vocal cords from surgery at the age of fourteen. The cancer supposedly developed from the excessive number of X-rays that Small's radiologist father used to treat the abnormal growth in Small's throat. The physical pain is not the only pain that Small experienced while growing up. The father's concealment of truth concerning the X-ray treatments as the cause of cancer is one of the greatest internal woundsthat runs through Small's memoir. The years of his youth in the memoir do not represent the support or affection that a young person should receive from his family. Small's family treated Small 
with abusive languages and actions, hostility, and indifference. Recounting the issues of his family members such as his father's concealment of truth, the grandmother's mental illness and his mother's closeted lesbianism, Small fills his graphic memoir with the physical and psychological traumas of his childhood and adolescence.

Barry's account does not concern physical illnesses like Small's, but her graphic memoir is equally ridden with the painful memories of her youth. The psychological trauma of an emotionally abusive relationship with her mother is represented throughout the narrative, and it is challenging to witness the emotional support given by any adult figures in her youth. Aside from the grandmother who occasionally keeps her company (who has a minimal narrative significance), there are barely any adults (family and non-family) around Barry who provides stable emotional support. However, the most traumatic memory that she presents in her memoir is the sexual assault she experienced as a child. Even though the narrative does not textually confirm the incident, Barry leaves multiple visual and textual clues that allude to her darkest trauma in her childhood that involves a sexual encounter with an adult male.

To illustrate these inexpressibly painful memories, the two artists use a common tactic: they represent the memories of trauma only or primarily using visual images while omitting the texts that clarify the images, creating a gap between words and images. Addressing children's illustrated texts, Perry Nodelman argued that "images [...] explain or clarify words and each other” (viii). However, what happens when the text neither explains or clarifies the image and vice versa in an illustrated text? Nodelman goes further and complicates the relationship between words and images by stating that illustrated texts require the implied viewer "to search the pictures for information that might add to or change the meanings of the accompanying texts" (18). This complication in the interplay of images and words can be further applied to graphic 
narratives. Writing on graphic novels, Illana Larkin claims, "Due to the dual medium of text and images that they utilize, any reading of a graphic novel must take the interplay of words and pictures into account” (183). The viewer of illustrated texts must take into an account -- either consciously or unconsciously -- that there are gaps created between images and texts, and they must fill in the gaps by making a coherent narrative between the two modes that, at times, play together or against each other. The viewers of the graphic memoirs must engage with the duality of visual and textual narratives in order to make a coherent interpretation of the complex autobiographical accounts of Barry and Small.

In Lynda Barry’s One Hundred Demons, the chapter, “Resilience,” is a notable chapter where Barry successfully utilizes the duality of narratives that makes the inexpressible expressible. The chapter comes from Lynda ${ }^{1}$ 's adolescence, but she moves freely between two memories: the memory of her first kiss as an adolescent, and the memory of her sexual encounter as a younger child. As Lynda in her adolescence begins to get involved in a physical relationship with a boy, she suffers an internal agony. Barry does not directly explain or clarify where this agony stems from, but instead briefly touches on the fact that she "already knew too much about sex, found out about it in harsh ways" (65). What comes after this statement is the image of Lynda as a younger child, looking up at an adult male figure who tries to lure her into following him by saying, "Hey there, sweetheart. Do you and your dolly want to go for a ride?” (72). One of the artistic appeals of Barry in Demons is the subtlety of her narrative. Although her memoir is filled with dark memories of her childhood and adolescence, it is difficult to perceive it in such a

\footnotetext{
'When referring to Lynda Barry as a character in her graphic memoir, I use "Lynda" instead of "Barry". This is to respect her concept of "Autobifictionalography", an autobiographical account that embodies fictional elements. Considering her view on her autobiographical account, I see it appropriate to refer her as "Lynda" to emphasize the fact that she is a character in her memoir, as much as she is the life writer. I will also use "David" when referring to David Small as a character in the narrative for the same cause.
} 
way immediately because of the cheerful and garish visual elements of her design that utilize bright colors and childlike illustrations. However, in the chapter of "Resilience,” Barry's representation of her memories become complicated and challenges the viewer to take agency in interpreting the subtle ways in which Barry communicates. While texts do not confirm this incident and focus more on her views on the subject of resilience, the visual image of Lynda encountering the faceless adult male alludes to a sexual assault in a grim and devastating way. The memory of her physical and psychological pain is silenced in this scene by the omission of the text that narrates the incident directly. Instead, the image is speaking for her in illustrating the inexpressible memory of her childhood trauma.

Silence is also effectively utilized in Small's Stitches as a defining tactic of dual narrative. Small's memoir is filled with the memories of physical pain since his narrative mainly follows the development of his cancer diagnosis and treatment through childhood and adolescence. Nevertheless, the physical pain he experienced is not only limited to his illness and Small, like Barry, omits texts while visually illustrating pain to express the inexpressible memories of trauma. When Small stays with his mentally unstable grandmother in his childhood, he is distressed by her violent personality and harsh ways. The grandmother grabs Small's wrist and drags him up the stairs to wash him in the bathroom. The young Small's face in the illustrations is filled with terror and pain. While the visual images of pain is vividly represented, the only text that accompanies his pain in this memory is the short cry of "Aahhhhhhh!” (94), and Small does not narrate or explain this memory with other words. Another example is found when Small has a surgery to remove the abnormal growth in his throat and sees the wound onhis neck for the first time. He unwraps the bandages on his neck, and the scarring image of his wound is revealed, followed by the image of the wound filling up the entire page situated in the 
next page (192). Small looks at himself in the mirror in sideways and his half-open mouth indicating the inexpressibility of a traumatic experience. The representation of witnessing his wound does not contain any words. It simply illustrates the shock and the pain of his memory. The interplay of words and images in graphic narratives serves as a powerful tool for artists who deal with traumatic life accounts. Elaine Scarry in The Body in Pain (1985) illuminates the inexpressibility of physical pain. Scarry claims, "Physical pain does not simply resist language but actively destroys it, bringing about an immediate reversion to a state anterior to language, to the sounds and cries a human being makes before language is learned” (4). For those with traumas that significantly impact their lives, talking about the traumatic memories can simply be impossible since words often elude them. Expressing the inexpressible memories of trauma with words is not only painful but it falls short in truly expressing the memory of physical and/or psychological pain. The biggest benefit and appeal of the graphic narrative for artists creating traumatic life accounts is the duality of narrative that allows them to switch back and forth from words and images for the task of showcasing their painful memories that are difficult to express. Barry and Small both successfully utilize the tactic of silence in expressing their inexpressible childhood and adolescence traumas.

When asked to speak about her mother who was depicted as emotionally abusive in Demons, Lynda Barry simply answered, “I think I don’t want to talk about that” (Kois). It is the graphic narrative that offers the artists an outlet to elucidate their painfully emotional memories without having to talk about it. 


\section{“The Thing Itself”: Visual Metaphors of the Inexpressible}

Another powerful visual tactic utilized by both artists is visual metaphor. In Unflattening — formerly a dissertation on graphic narrative in the comics form and later published by Harvard University Press — Nick Sousanis claims that perceptions from visual images are "not mere decoration or afterthought, but internal to thought, a fundamental partner in making meaning” (81), and that they provide "multidimensional sight [...] where existing barriers tumble and creative possibilities flourish” (82). The two graphic memoirs of Barry and Small show how the interplay of words and images forms an intricate narrative and create a space where new possibilities of meaning for their traumatic pasts can be born within the structure of unique storytelling.

As previously mentioned, the chapter, "Resilience," in Demons is the most poignant account where Barry recounts her childhood trauma. Barry not only utilizes the tactic of silence by omitting the text in illustrating her sexual trauma with images, but also brings togetherseveral symbolic images of visual metaphor in her memoir that enable "multidimensional sight" where “creative possibilities flourish” as Sousanis puts it (82). For each chapter, Barry provides a visually rich collage in two spread-pages that serves as a cover for the chapter. These cover images feel tactile and are full of materialities that evoke a sense of nostalgia for childhood and more specifically girlhood. However, these collage images are more complex than they appear on the surface. Discussing Barry’s collage format, Kirtley argues that it “allows Barry to depict simultaneous selves in conversation through picture, word, and ephemera and forces the reader to make sense of these dialogues. This postmodern approach challenges a singular, unified identity” (174). Postmodern texts often break traditional boundaries of narrative, materials, forms, and perspectives. Through her collage-making, Barry creates a complex narrative of her 
memories so that the viewer must take an active role in interpretation. When the viewer first looks at the collages, it is difficult to gauge the heaviness of the subject because of its style. However, after unpacking the hidden metaphorical meanings and nuances of the collages in the beginning of each chapter, the viewer can realize how emotionally and metaphorically heavyhanded this collection of images are. In the collage of the chapter, "Resilience," the important images to pay close attention to are the various visual representations of Lyndas as a child and adolescent that creates multiple selves in a visual dialogue. There are four images of Lynda in total and the one on the far-right side of the spread-pages is particularly noteworthy: Lynda represented as her doll. The dolly image appears in the chapter when Lynda encounters the adult male who tries to lure her into following him (72), suggesting a memory of her sexual trauma. In the scene, Lynda is holding the doll in her arm, and the doll is wearing a blue dress and a sleek bob hairstyle. Right next to this scene is Lynda as an adolescent shown in a similar visual representation with her doll; the same blue shade of clothing and a sleek bob hair. Throughout the entire chapter, adolescent Lynda's hair exactly matches the doll that was present when the suggested sexual assault occurred. Following on the chapter's collage, the doll is situated here as the main image for the chapter's title, "Resilience." The doll is laid on its back in the same space where the sexual assault occurred — verifiable from the same design pattern of the grass and flowers of the scene - but except that it is the nighttime here, as if time has considerably passed after the incident. The doll's eyes are vacant as if it is dead or perhaps lost her soul. This image is effectively carried out through the inanimate human form of the doll. While lying on its back, her left hand is placed on the low middle part of her body. Next to the doll, there is a giant figure of a bug that seems to be crawling on the doll between her legs and this bug is also connected to a tall, blue, and devilish-looking figure who is standing tall in the space where the mysterious adult male was located in the scene of the sexual trauma (72). The image of the inanimate doll 
withthe vacant eyes being left at the site of trauma depicts the part of the narrative that was not verbally elaborated by Barry: the aftermath of her trauma and Barry's memory of the incident too inexpressibly painful to express in a singular medium of text. The doll is left at the site of trauma and thus indicates something lost in Barry's childhood: innocence of her childhood, forever haunted and haunting Barry continuously. The symbolic representation of her trauma through visual metaphors is further amplified with more death images including the ghost that holds the sign, “Today’s Demon: Resilience” (63). On the opposite side, there is a picture of Lynda as a young child and her eyes are covered with translucent orange tape as if to visually and metaphorically suggest the rose-tinted glass that the adults put on children to endorse "resiliency of children" and "forgetting” of traumas (66) that Barry strongly challenges in the chapter.

Similar to the tactic of silence previously analyzed, Barry does not address her trauma directly. There is no mention of anything directly related to sexual assault or who the mysterious adult male that caused Lynda sexual trauma is supposed to be. Instead, she uses visual metaphors to unpack her memory with various materialities. Like Kirtley claimed, her "scrapbook" that is filled with visual metaphors is created "to frame her life and girlhood from numerous points of view and through different mediums simultaneously” (175). As one’s account of life does not occur at a single point or another, it is consistently reshaped and reformed by the act of remembering and forgetting, adding continuously evolving perspectives. This can be equally applied to one's trauma. In Barry's case, the viewer can witness that there are multiple Lyndas that are affected by her memory: the child at the very site of memory, the adolescent advancing to a physical relationship, and the adult recounting and reshaping all through the unique storytelling of words and images. All of these Lyndas in different stages in her life are having conversations through "different mediums simultaneously" as Kirtley 
described it. The duality of narrative is crucial in this task since it provides a multidimensional space that signals that more than a singular meaning or perspective can coexist. The materialities that Barry utilize such as glitters, stickers, photographs, and origami are the sensory anchors that help her bring back the memories of her childhood and adolescence while recounting emotionally heavy subjects.

Without unpacking them, the viewer cannot fully make sense of the dialogues between her multiple selves represented in the memoir in a complex way.

As Small's memoir is equally ridden with painful memories of his trauma, he also skillfully utilizes visual metaphors that speak for him. Throughout his childhood and adolescence, Small's mother treats him with anger and abuse. In a scene where young Small witnesses his mother’s anger, Small compares his mother's fury to a "black tidal wave” (46). When his mother is furious at him and verbally or/and physically abuses him, Small illustrates his young self being swept up by black tidal waves $(47,123)$. In the image of David as a child being tossed and tumbled by the gigantic waves of his infuriated mother, David is represented as helpless and defenseless. Like the waves of ocean that can fatally immerse a person, themother's fury is overpowering and fearful.

The visual metaphor is further utilized when Small's therapist is represented as the White Rabbit character from Lewis Carroll’s Alice’s Adventures in Wonderland (261). The psychoanalytic interpretation of Alice that views the White Rabbit as a medium that prompts an exploration of the subconsciousness is often represented through different media in popular culture. The White Rabbit in Small's memoir also prompts young Small to explore his subconsciousness. When the therapist in the image of the White Rabbit helps Small realize that his mother doesn't love him (255), the visual representation is almost too difficult to tell whether it is the Rabbit that reveals the truth or if it is in fact Small himself from his subconsciousness. 
The images of the Rabbit's and Small's eyes are juxtaposed so that is hard to distinguish the two. In many cases, therapists do not simply give answers to their patients. Instead, they try to help them realize the deeply buried truths on their own because the patients are the only ones that have the direct access to the deepest and most painful memories of their lives. The visual representation in this scene represents this aspect of therapy. The White Rabbit is merely an aid that guides Small through the painful paths to his traumatic memories, and it is Small himself who now faces the harsh truths of his life. The visual metaphor continues to illustrate his pain after the scene. Small falls down to the ground, grabs the leg of his therapist, and starts shedding tears. His tears turn into the pouring rain soaking all of Small's hometown, Detroit, and the creased face of Small is shown with agony. It is the viewer's responsibility to interpret the heaviness of Small's emotions from these images that serve as metaphors. Like Barry, Small does not talk about his painful memories directly. The more emotionally painful the memories get, the less texts directly accompany the images and clarify them. The gaps get bigger and bigger and the viewer must fill in the gaps as they interpret the duality of narratives in these artists' memoirs that may hold more than a single truth. The absence of words that directly address the traumatic memories are filled by the visual metaphors that unpack them without having to speak about them. Sousanis illuminates on the nature of words and images by claiming that "images is when text is always about" (58). Sousanis further points out: "The visual provides expression where words fail [...] and what can be made visible when we work in a form that is not only about, but is also the thing itself” (59). The two authors, Barry and Small, use the particular medium of graphic memoir to unpack their memories in a form that utilizes more than the words that is always about, limiting the life writers to express the inexpressible memories of pain and trauma. They illustrate the "thing itself"; the demons of their traumatic memories that 
haunt them to speechlessness. The duality of narrative in graphic narrative provides the artists a multidimensional space to communicate their pain where words can only fulfill them partially. 


\section{CHAPTER II: BODIES, MATERIALS, AND WITNESSING: THE EMBODIED AND MATERIALIZED SUBJECTS OF TRAUMA}

One writes in order to become other than what one is. - Michel Foucault

\section{Embodied Subjects and Becoming a Witness}

In The Limits of Autobiography: Trauma and Testimony (2013), Leigh Gilmore makes an illuminating remark on autobiographies that deal with trauma:

Yet conventions about truth telling, salutary as they are, can be inimical to the ways in which some writers bring trauma stories into language. The portals are too narrow and the demands too restrictive. Moreover, the judgement they invite may be too similar to forms in which trauma was experienced. When the contest is over who can tell the truth, the risk of being accused of lying (or malingering, or inflating, or whining) threatens the writer into continued silence. (3)

As I noted in the previous chapter, the accounts of trauma are often too emotionally heavy and complex to contain in a singular medium of text. The inexpressibility that the writers of trauma often experience is too challenging to be assuaged through a single form of narrative. Even when a traumatic account is expressed through the narrow and restricted portals, it often becomes a target of censorship because of its inherent nature of truth-telling and its reception. In Graphic Women: Life Narrative \& Contemporary Comics (2010), Hillary Chute claims that the form of graphic narrative can serve as an "enabling role of the visual in self-articulation and in representing the processes of memory, especially traumatic memory” (7). In graphic memoirs that deal with childhood trauma, there are innately more than a single representation of self because the authors construct representations of their selfhoods through multiple images of their 
changing bodies from childhood to adolescence and adulthood from which they attempt to unpack their painful memories. The representations of their bodies in both images and texts become containers of their embodied memories and the sites of storytelling. Their embodied subjects constantly evolve as the representations of the bodies change throughout the narrative. On the subject of embodiment and life narratives, Sidonie Smith and Julia Watson in Reading Autobiography: A Guide for Interpreting Life Narratives (2010) make a compelling argument.

[B]ody is a site of autobiographical knowledge because memory itself is embodied. And life narrative is a site of embodied knowledge (a textual surface on which a person's experience is inscribed) because autobiographical narrators are embodied subjects. ... The ability to recover memories, in fact, depends on the material body. There must be a somatic body that perceives and internalizes the images, sensations, and experiences of the external world. (49)

What Smith and Watson illuminate is the significance of the body in autobiographical accounts and how the life writers' perceptions and representations of their body as a site of embodied knowledge is an important part in telling the story of one's life. Smith and Watson primarily address life narratives that utilize the textual mode of a narrative, but the embodied subjects become rather literal in the graphic narratives of life. With the multiple autobiographical avatars and voices that the authors construct through their unique interplay of words and images in graphic narrative, the life accounts that the authors present to the audience become more than a single and static truth. Because of this fundamental aspect of self-representation in images and words in graphic narratives, there is not only an ongoing tension between the older and the younger selves in the narrative voices of the protagonist and the narrator, but also there are tensions between multiple selves in various stages of bodies that the authors present throughout 
their narratives. Through their embodied subjects, the authors of graphic memoirs are "materially reimagining trauma” (Graphic Women, 2) as Chute explains. These embodied subjects of traumatic memories refuse to be single-sided or frozen in time. The format of graphic narratives enables the self-articulation in dual narratives that represent changing bodies. The life writers' multiple bodies represented in the graphic format are constantly in conversations with each other and create multidimensional truths of one's life.

\section{The Stories of Bodies}

It is fair to say that David Small's Stitches is literally the story of a body. What this account of life chronicles is the body of David through his childhood, adolescence, and adulthood tracing the memories of the abuses he received from his family members, the abnormal growth he developed on his neck from the excessive number of X-rays, the cancer treatments and surgeries, and the recoveries from both physical and psychological wounds he attained through the years of changing bodies. Lynda Barry’s One Hundred Demons also presents various images of Lynda's changing bodies while she experiences and recounts the memories of her traumas. The prominent life stages that these graphic narratives present are in three key parts: childhood, adolescence, and adulthood. Not only do their traumas follow the narrated "I” ("the protagonist of the narrative” Smith and Watson, 73) through all stages of their lives while transforming their shapes and haunting them incessantly, but also the format of these autobiographical accounts is not simply linear as much as more conventional, single-text autobiographies. Instead of following the chronological order of their lives, both authors go in and out of their sites of storytelling, jumping freely from one memory to another, representing the shapes of their traumas that invade all aspects of their lives. 
Small’s Stitches starts with a full-bleed page of black background with the sentence, "I WAS SIX” in white ink (9). It presents as an image of an X-ray that heavily influences in his life. The images that follow another full-bleed page of "DETROIT" (10) are black and white watercolor images of his early childhood while growing up in Detroit. Because of this watercolor quality of his artwork, the color scheme of his graphics looks gray and shadowy, which is strikingly different from Barry whose artistic foundation is in the rather conventional style of comics (when it comes to the basic structure of her sequential art) that utilizes vibrant colors, four panels in a single spread-out presentation in two pages, and defined lines of the gutters. The gutters in Stitches, on the other hand, phases in and out throughout the narrative, blurring the lines between the real and the re-imagined visions of Small. These X-ray-like images are a medium in which the narrating "I” (“'I' who tells the autobiographical narrative” Smith and Watson, 72) of Small reviews in order to locate and define the symptoms of his traumatic memories. There are a few prominent images that specifically strikes as X-rays. The image of David as an adolescent after his father reveals the truth about his cancer (288), the images of his scars on his neck after the second surgery (190-191), his screaming self(ves) (234), and finally David's mother and grandmother, standing inside and in front of the asylum and clearing the way for him to follow ,and this full-bleed page resembles an X-ray image of a human ribcage(324). His family members are at the heart of David's narrative (visually situated in the ribcageresembling asylum) and inflict constant pain and flashbacks. If Small's narrative starts with the $\mathrm{X}$-ray image that unpacks his life stories and locate the site of his pain and trauma, it is the end of his narrative that indicates the core of his central issues. Family and their secrets as central problems are now exposed and revealed, following with the inverted image of X-ray with the assertion, “I didn’t” (325) that demonstrates the lesson-learned through this nonfictioncoming- 
of-age narrative. He is not following in the footsteps of his family who fills their own lives with violence, concealment, betrayal, shame, guilt, and silence.

The representations of changing bodies throughout the narratives have a crucial role in relation to the life writers' traumas. The X-ray-like images are essentially images of David's bodies in different stages in his life. In these visually rematerialized representations of bodies, the physical and psychological trauma of the past become visible and concrete on the surface of the paper. While David in his adolescence is looking at his wound on his neck in front of the mirror with his half-open mouth indicating the inexpressibility of his pain and trauma (190), Small as the narrating "I" goes back to the site of his trauma as a witness, not solely as the victim of his past. What enables this literal "witnessing" of his own trauma is the unique duality of narratives in graphic narratives. As Chute points out, "The art of crafting words and pictures together into a narrative punctuated by pause or absence, as in comics, also mimics theprocedure of memory” (4). The dual narrative of graphic memoir is similar to one’s process of memorymaking and recounting of memories. For the sufferers of traumas, the obsessive recounting of memories and flashbacks are common and defining symptoms of trauma. As painful as they can be, these symptoms are necessary processes in recovering from one's trauma. In order to recover from a traumatic memory or more precisely, to live with the traumatic memory, as one cannot "unlive" the moments of their trauma, one must step in and out of the event in memory to gain multiple and evolving perspectives. According to an article from Northwestern Now, each time we remember an event, our memory changes its shape. "Every time you remember an event from the past, your brain networks change in ways that can alter the later recall of the event. Thus, the next time you remember it, you might recall not the original event but what you remembered the previous time” (Paul). Through the process of remembering, the victims of traumas constantly 
craft new truths of their pasts, and the format of comics has a vital role in this process. As Nick Sousanis unpacks the science of drawing in Unflattening, there is a profound correlation between the act of drawing and our conceptualizations of self.

Drawing, as Masaki Suwa and Barbara Tversky suggest, is a means of orchestrating a conversation with yourself. Putting thoughts down allows us to step outside ourselves, and tap into our visual system and our ability to see in relation. We thus extend our thinking — distributing it between conception and perception — engaging both simultaneously. We draw not to transcribe ideas from our heads but to generate them in search of greater understanding. (79)

Sousanis' analysis of drawing directly corresponds to Scott McCloud's statement on cartooning when he remarks, “cartooning isn’t just a way of drawing, it is a way of seeing” (31). Through the process of drawing one's body and its changing forms that contain the trauma, the narrating "I" sees their traumatic memory in relation rather than a static event trapped in one moment or another. The narrators are not simply representing their memories to "transcribe" them but to generate perspectives of their trauma as both the victim (the narrated "I") and the witness (the narrating “I”). Through the visual representations of their evolving bodies as containers of traumas and sites of storytelling, the life narrators tap into the embodied subjects of trauma where a single language fails to explicate at the fullest. In graphic memoirs, there are tensions between the multiple narrated "I"s and the narrating "I”. In Graphic Women, Chute compellingly unpacks this complexity of multidimensional perspectives.

It is a way to visually present a tension between the narrating "I" who draws the stories and the "I" who is the child subject of them. ... the comics form not only presents a child protagonist and an adult narrator but also gives voice simultaneously to both 
perspectives, even within the space of a single panel, layering temporalities and narrative positions. (5)

Within the spaces of panels that graphic narratives utilize, both the child protagonist (in Barry and Small's cases child and adolescent protagonists) and adult narrator share complex and interactive narrative positions. They are separate entities of a protagonist and a narrator but a single actor in the life account they represent at the same time. Just as one's body is an everevolving materiality, the evolving perspectives of a life account are represented with multiple sites of storytelling through the changing bodies of temporality. As the author moves from one memory to another, each embodied subjects provide the sites of storytelling where multiple perspectives can evolve and coexist in one’s life narrative.

\section{Memory and Materiality}

How do we remember an event, a period, a phase of our lives? It might be an old vinyl that has been gathering dusts in the shelves you accidently pulled out one day that suddenly sparks the memories of your early twenties. It might be a Christmas decoration that you and your partner made together years ago that has been sitting in the back of the storage room, halfforgotten. It might be pages of photographs that you kept in your family album that you occasionally share with your family on holidays. It might be a small pinch of fur that you kept in a tin to commemorate your first pet. It could be anything (no matter how economically invaluable it may seem to others) that sparks our memory, but one thing certain is that the things that evoke our memories are always connected to our senses. Whether it be a sight, smell, sound, taste, or touch, it deeply connects to our memory-making and remembering. On the subject of memory and materiality, Smith and Watson claims,

Memory, apparently so immaterial, personal, and elusive, is always implicated in 
materiality, whether it be the materiality of sound, stone, text, garment, integrated circuits and circuit boards, or the materiality of our very bodies -- the synapses and electrons of our brains and our nervous systems. Memory is evoked by the senses -- smell, taste, touch, sight, sound — and encoded in objects or events with particular meaning for the narrator. (27)

We might not metacognitively recognize a moment when a memory is being made, but looking back on a memory, we know for certain that our memories are always tied to our senses of the pasts. The reason why the business of "retro" aesthetics is so timelessly popular (just switching from decades to decades as time goes by) is exactly because of the relation between our memory and materiality. The materials that we remember seeing, feeling, tasting, smelling, and hearing evoke the memories of our bittersweet past lives and we attempt to relive those moments in futile efforts.

Materiality has a deep correlation with graphic memoirs. Because one’s memory is not only verbalized but also visualized by the narrator in graphic memoirs, it becomes possible for the narrator to evoke a memory with more various senses, and they can do so for themselves and the audience who may share a similar memory or a memory of a similar time in one’s life. Many graphic memoirs integrate materiality into their narratives and Raina Telgemeier’s graphic memoir Sisters (2014) is a good example. At the end of each chapter, Telgemeier presents a fullbleed images of specific objects that connect directly to a memory that she unpacks in the chapter. These objects are containers of her memory and the sites of her storytelling. Photographs of oneself or family members of the narrator are also important material objects in memoirs. Art Spiegelman in Maus, Alison Bechdel in Fun Home: A Family Tragicomic, Cece Bell in El Deafo, Small in Stitches, and Barry in Demons all integrate photographs in their life 
narratives, and photography has been an important subject in life writing. In Family Frames: Photography Narrative and Postmemory (1997), Marianne Hirsch analyzes family relationships in autobiographies and how the structure of family photography challenges and influences the conception of family. Addressing the use of photographs by contemporary life writers and its impacts, Hirsch claims,

Contemporary writers, artists, and filmmakers, as well as contemporary cultural critics, have used family photographs in their work, going beyond their conventional and opaque surfaces to expose the complicated stories of family relation — the passions and rivalries, the tensions, anxieties, and problems that have, for the most part, remained on the edges or outside the family album. Artists and writers have thus attempted to use the very instruments of ideology, the camera, the album, and the familial gaze, as modes of questioning, resistance, and contestation. They have interrogated not only the family itself, but its traditions of representation. (7-8).

This analysis speaks directly to the case of Small's memoir. The photographs of Small's mother, father, and himself are not representations of his family nostalgia. The specific photographs and the captions Small provide subverts the traditional stroll-down the family memory lane with a nostalgic smile that traditional life accounts may integrate in their memoir. The photographs and his commentary only amplify the tensions and problems of his family with its material presence that makes this horrid life account far too real.

As materiality plays an important role in graphic memoirs, Barry's Demons is an example that is certainly the most material, the most tactile, and naturally the most concerned with the subject of memory. As Barry retraces her memory, materiality plays a central role throughout her narrative. As much as Barry's memoir is about remembering the past, it is also about how to 
illustrate the demons of the past; how to perceive and interpret the past to live with them. If we take the materiality of Demons into account when analyzing her graphic storytelling, how does the materials of Barry's pasts interact with the materiality of her book? What are the purpose and function of her tactile and material representations of her often traumatic memories? The format of Barry's memoir is a fundamental facet of her storytelling rather than an incidental materiality. With its format that resembles children’s picture books and activity books, Barry compellingly summons the demons of her pasts with the materials that she adequately withholds; the ephemeras of her childhood. In the next segment in this chapter, I will examine the materiality of Barry's memoir and how the format of her memoir plays a vital role in her content.

\section{Demons, Materials of Childhood, and Therapeutic Writings of Trauma}

"Form Follows Function" is a maxim coined by a twentieth century American architect, Louis Sullivan. What this famous maxim suggests is that the format that artists utilize plays a more significant role than just a few recognizable aesthetic purposes. In fact, the format plays the fundamental role for executing the artistic object's function. In her article that deals with Art Spiegelman's graphic memoir on the September Eleven Attacks, In the Shadow of No Towers (2004), and its connection to materiality, Michelle Ann Abate discusses how the physical form of a book significantly impacts the way that it is treated and interpreted (41). Through her compelling analysis, Abate reveals how the materiality and physicality of a text can connect directly to the content and the concepts it conveys. Similar to Spiegelman's memoir, the materiality of Barry's Demons also reveal something significant about the characteristics and function of her book. Many intersecting genres are involved when perceiving Barry’s text: graphic memoir, life narrative, cartoon, nonfiction, and "autobifictionalography" which is the 
definition of the genre Barry assigns to her own book, pointing out the thin line between fiction and one’s autobiographical account. The applications of genres concerning Barry’s book are mostly obvious, and obvious for critics and comics and life writing scholars if not for the general audience of her book. However, what is often overlooked is the examination of how the material and physical format of her book is presented to the audience as well as how those material aspects impact the reception and the interpretation of the book.

When Barry first introduced these comic strips to the world, they were not originally released as a full volume book. She originally published the cartoon strips on Salon.com as web comics from 2000 to 2001 which was later collected as a print collection in 2002. When One Hundred Demons was released as a web comic, the material format rather resembled the genre of comic strip found in newspapers. Instead of each panel being laid out side-by-side, she utilized the conventional four panel layout of the comic strips; two of them side-by-side, and the other two on the bottom. However, this format seems to work against the narrative and does not deliver the same emotional impact as the collected book format does. Instead, the collected book edition lay out the comics strips side-by-side and two panels on a single page, resulting in the book looking more like the format of a picture book, rather than a regular hardcover, paperback, or graphic novels that are usually in the portrait layout rather than the landscape. The landscape layout is mostly strictly reserved for children's picture books. The long on the side, landscape layout of a book that is filled with more images than words is one of the conventional formats for books that are read by children. Many classic and landmark children’s picture books such as Goodnight Moon by Margaret Wise Brown, Snowy Day by Ezra Jack Keats, and Where the Wild Things Are by Maurice Sendak all represent this landscape format. Then, what is the purpose of this material formality in children's picture books?

In Words About Pictures, Perry Nodelman discusses the format and design of children’s 
picture books and their impact on the viewers' responses to the stories. Nodelman remarks, The actual physical appearance of individual books is just as obvious an example of how prior expectations control our responses to stories: it influences our attitude to the stories the books contain before we even begin to read them. ... and as a result we respond differently to the same story in different formats; ... but these differences are as much a matter of convention as of technical limitations. ... [T] [he difference is less in the books themselves than in our general expectations. (44-45)

What Nodelman illuminates in this passage is that we, as viewers of texts, hold certain expectations about the content of a text by having prior knowledge of different formats of texts. Nodelman uses examples such as Beatrix Potter’s The Tale of Peter Rabbit (1902) and Maurice Sendak’s Nutshell Library (1962), and explains how the viewers expect fragile and delicate stories from smaller size books, whereas we expect more rambunctious and energetic stories from larger books. As I mentioned, Barry’s Demons is much wider than most graphic narratives or any other genres of books written for adults. The format of her graphic memoir is similar to the kind of picture books for children with landscape layout, except that her book is thicker and heavier than children's picture books that indicate the heaviness of her subjects and her personal stories. Then, what can we say about this formatting decision on Barry's memoir, and what can we say about the viewers' expectation about the book?

As much as Barry's graphic memoir is about the personal histories of her life, it is also about the ephemera of growing up and remembering. It is also about bringing back her memories and witnessing them again as Barry suggests in the introduction by stating through one of her “demons”, “[S]he started to love watching them come out of her paint brush” (12). Her book is the result of practices where she summoned the demons of her pasts. The demons reside in her 
past memories, and they are mostly located in her childhood and adolescence. The material format of her book is designed to execute this practice of summoning her demons because it is much like a picture book; a format of reading that one engages with in their childhood; the material that one holds in the earliest memories of their reading experience. As many picture books have more illustration than text, Barry's memoir is also extremely heavy-handed with images. The two-spread pages that serve as cover art for each chapter are filled with small illustrations and tactile art pieces that are made with materials that evoke the memories of childhood art classes: glitter, colored-paper origamis, googly eyes, stickers, feathers, flowerpattern clothes, and sequins. As our memories are tied to the objects that evoke certain senses that are related to our memories, Barry's materiality in her memoir also strongly evokes a distinct time period of her life and the audience's life. Because the book is wide rather than high, the audience must read the book in a horizontal manner, rather than vertical. The act of readingis usually done from top to bottom, as one processes information from reading. The act of looking, on the other hand, needs a more holistic process. It doesn't only move horizontal, but it also moves back and forth and must utilize repetition. For example, a landscape painting or photograph is usually wide, as the term landscape is now utilized as the particular wide layout format. Landscape art requires us to see the width and consider all the small parts of it to see the big picture. To fully see landscape art as a whole, we must see the rising sun behind the mountains in one corner, a farm on the other, the big oak tree in the middle, the purple clouds on the top, and the endless array of lavender fields in bloom on the bottom. This process cannot be done with the practice of reading that mostly utilizes vertical looking. It needs to move vertically and horizontally, from left to right, and from right to left, in multiple efforts. Without really looking at all the small parts, we cannot appreciate the bigger picture of a scene. This 
characteristic of a wide format applies to picture books. In his analysis on the picture book format, Nodelman includes picture books with wide formatting. He points out at the function of width:

[M]ost picture books are wider than they are high, ... The extra width of wider books allows illustrators to fill in the extra space around the people they draw with information about the places they occupy — their setting; and if we operate, as illustrators almost always do, on the assumption that such external appearances reveal internal characteristics, we learn much of character in such pictures through the details of background. (46)

Just like landscape art, the audience of a wider book is expected to look closely at the details, as Nodelman suggests. The audience must look at the details in the background and the spaces that the illustrators fill in to draw attention. If the explosion of visual representations that Barry presents to the audience was formatted to be read vertically from top to bottom and high rather than wide, the reader may feel less obligated to pay close attention to the details that expose the characteristics that represent Barry’s stories. The audience may "read” the images rather than "look"; "process" the information rather than "feel” them to get the bigger picture as they would with a landscape art. With the wide formatting that is utilized by landscape art and picture books, the audience of Demons must look at all consisting parts (from small illustrations in the chapter covers to the backgrounds, characters, and dialogues of Lynda's stories in the panels) and may have to go back and forth until they get the idea. In the previous chapter, I discuss the heaviness of the visual metaphors in the cover art for the chapter, "Resilience”. Without looking at the individual parts that the big picture consist of (as one would look at the tree, cloud, the farm, and lavenders in a landscape), the audience cannot receive the message of resilience that Barry tries 
to communicate in this cover art of the chapter. The wide format of a picture book not only evokes the memory of childhood, the memory of looking at pleasurable pictures in a book, but also enables the art of looking and an understanding what an image tries to communicate and illustrate rather than just deliver.

The wide picture book format also facilitates a private experience. Barry's Demons is not exactly a book that a reader would take to the subway to read during their commute or while waiting in the dentist's office. When you spread the book open, the size of the book is wider or just as wide as an adult’s body. It is extremely awkward to "hold" Demons and read it and requires you to set it down on a surface to read it comfortably. Since the book is very much a cross-over text, an adolescent or an adult reader may be concerned with the public eye because Barry's artwork that effectively brings back the tactile representations from her childhood and her unique style of cartoon. This specific physicality that the book embodies forces the reader to read it in a private space. This is important for the function of her narrative for two reasons: 1 . The practice of looking requires enough time and space. 2. The private stories that Barry presents to the audience are emotional and poignant. The private stories require private reading.

Another important element in the materiality of Demons is the part at the very end. Like Small, Barry provides photographs. However, the representation of her photographs is even more unconventional than Small's. The photograph that fills the whole page at the end of her narrative is Barry herself at her desk at home, drawing the demons with brush and ink in her pajamas as she prefaced in the introduction. While providing authenticity with the photograph of herself executing the act of her life narrative, she also provides a Do-It-Yourself kind of guide on painting your demons. She presents multiple images of objects she uses to paint the demons with commentaries and steps for the audience to follow. The photographs also show Barry herself 
showing the audience how to fulfill each step of the process, like an activity book for children. Like the wide format of picture books, this very end part of her book also evokes the sense of ephemera from childhood. Not only that, the activity book format also plays a central role in communicating Barry’s narrative purpose throughout the book. Barry’s book is about remembering the very private memories of her childhood and adolescence. They are often painful to witness and ridden with complex emotions. It is also about sharing those very private memories with the audience in a format that requires a private reading. Artmaking is the crux of it all. She uses the ephemera of her growing up; the materials that evoke the sense of childhood and adolescence to summon the demons of her past and re-experience the memories on the material surface to become the witness of her past, not only a victim, like Small does with the embodied images of his past. At the end of the volume, Barry invites the readers to do it themselves — for them to become the storytellers of their pasts through artmaking, not just the readers of Barry; to heal from the emotionally painful traumas that they might also carry like ghosts behind their backs. The book that the audience expects a private experience because its materials also expects the audience to create an experience of telling private stories.

\section{Art as a Therapy: The Healing Effect of Graphic Memoirs of Trauma}

When Barry is not making comics, she teaches comics at the University of WisconsinMadison and we can get a glimpse of her pedagogical persona in the very last part of Demons where she provides the "How-To" activity pages for the audience. Explaining her view on images and art-making in an interview with Dan Kois, Barry calls the "state of mind 'the image world' and feels it's as central to a person's well-being as the immune system.” It is a wellestablished belief that narratives with creative elements offer therapeutic effects to their writers 
in the study of life writing. Life writers may incorporate different creative outlets such as poetry, photography, visual/textual metaphors, and fictional elements when discussing their memories. In her article, “Therapeutic Effects of Writing Fictional Autobiography,” Celia Hunt discusses her research that examines the experience of students engaging in writing fictional autobiography for therapeutic purposes. She defines fictional autobiography as "creative writing that uses fictional and poetic techniques to capture self-experience, including physical and emotional experience, personal memories, and present and past relations with others” (231). Hunt specifically emphasize the importance of poetic and fictional language in this practice. She claims,

When writers consciously use fictional and poetic techniques to tell their story, they suspend the truth-telling intentions inherent in the 'autobiographical pact', and this changes the conceptual frame. Paradoxically it is this suspending of intentions associated with the truth of the self that makes fictional autobiography potentially a very powerful tool for exploring 'truths' that lie beneath the surface of conscious self-knowledge. (234) Hunt's notion of fictional technique in life writing in order to suspend the truth is also hinted at by Barry in the introduction to Demons. Barry asks questions pertinent to the study of life writing. "Is it autobiography if parts of it are not true? Is it fiction if parts of it are?” (7). Responding to this question, Barry calls her narrative "Autobifictionalography" in the beginning of her graphic memoir. Her question about the fictional elements of autobiography signifies that the she is aware of the destabilizing nature of truth in autobiography. Since one's account of their life is situated in one's memory of the past, it cannot avoid being somewhat fictional by degrees. However, Smith and Watson states that memory works "not only as a destabilizer, but also as an authenticator" (22). With the use of a narrative that contains fictional elements and the tactics of graphic narratives, Barry and Small's memoirs work as therapy for them and audience with 
similar experiences and provide healing. At the end of each narrative of Barry and Small, the two artists seem to somewhat make peace with their painful memories of childhood. In the last chapter of demons, "Lost and Found," — as even the title seems to suggest how she was "lost" in the memories of pain so that she could not forget, but has now been "found" by the comforting outlet of cartoon-making -- Barry talks about how classified stories in the newspaper "died" inside and how she "loved tragic endings" in stories (211). She also discusses how she never thought of herself as a writer, but how she became one with the help of the visual narrative of cartoon so that she finds her true storytelling identity. Borrowing the form of classified ads that she loved as a child, Barry concludes how the story helped her finding happiness. "Lost, somewhere around puberty. Ability to make up stories. Happiness depends on it. Please write” (216). Following the statement, Barry includes pages of directions for the readers to paint their own demons. It is clear that the act of telling the story of her life by using visual narrative helped Barry cope with the pain of her childhood. Telling a story of one's own lives enable a healing effect for a writer. In the cases of graphic memorists, the visual narrative of images amplifies its effect even further by offering creators an outlet where they can illustrate their painful memories when words fail to do so. Barry and Small both re-materialize their memories through embodiment and the materiality utilized in their narratives. Through the re-materialized memories of their painful traumas, the authors become other than what they are; they become the witness of their pasts, as well as victims. The narratives that they illustrate provide multidimensional sights and facilitate a conversation of the multiple selves in the sites of their traumatic memories via storytelling. Graphic narrative with its unique format and its rhetorical benefits offers a venue for healing and new possibilities of meaning. 
CHAPTER III: CIRCLING BACK TO THE PAST: FRAGMENTED TIME, AND THE ETHICS

OF LIFE NARRATIVES

\author{
“Our perception of 'reality' is an act of faith, based on mere fragments" — Scott \\ McCloud \\ "Memory would be of no use if it were strictly faithful” - Paul Valéry
}

\title{
Frame, Gutters, and Time
}

Graphic memoirs utilize sequential art, and it is the fundamental format of comics and graphic narratives. According to Scott McCloud in Understanding Comics: The Invisible Art, sequential art is defined as "juxtaposed pictorial and other images in deliberate sequence, intended to convey information and/or to produce an aesthetic response in the viewer” (9). Sequential art presents multiple images in a deliberate sequence and thus creates a unique narrative pattern and a representation of time. The medium of graphic narrative utilizes sequential art where the frames and gutters are vital parts that frame the narrative. This unique interplay of frames and gutters, what is inside the frame or included in the scene and what is outside the frame or not shown in the scene, creates a unique narrative pattern where the viewers' participation is central to its functionality. Addressing the dynamics of frames and gutters in comics, McCloud introduces an important term called “closure” (63). The reader of comics not only perceives the messages inside the frame but also actively engages with the narrative to "fill in the gap" by assuming what is not presented to them in the frame. The reader constantly engages with the format to see what happens in the gutter, in the space between the presented moments. McCloud explains, 
This phenomenon of observing the parts but perceiving the whole has a name. It's called closure. ... [A]udience is a willing and conscious collaborator and closure is the agent of change, time, and motion. ... That space between the panels? That's what comics aficionados have named "the gutter.” And despite its unceremonious title, the gutter plays host to much of the magic and mystery that are at the very heart of comics! Here's the limbo of the gutter, human imagination takes two separate images and transforms them into a single idea. (63-65)

Because of frames and gutters that the authors utilize, graphic narratives demand a task ofseeing and also seeing what is beyond. The audience observes the parts of a narrative in the presented scenes in the frames, and imagines the parts that are not presented to them in the gutters. This distinct phenomenon of closure in sequential art enables a narrative to have a unique representation of time. Unlike films or animations, graphic narratives use an array of static images woven together to create a scene. This array of images allows multiple moments in time to exist visibly in the frame and invisibly in the gutter simultaneously. McCloud explains, "But unlike other media, in comics, the past is more than just memories for the audience and the future is more than just possibilities! Both past and future are real and visible and all around us!" (104). As McCloud remarked, audience of sequential art is able to witness many scenes at the same time whereas, in films and animations, audience can only see one scene at a time. Because of this unique format of sequential art provides, audience can see past, present, future in several scenes, and in the frames and gutters at the same time. Time in sequential art is fluid and flexible. This fluidity and flexibility in the representations of time in graphic narratives are specifically useful for the life writers who unpack their traumatic childhood memories. These qualities in graphic narrative are especially useful for them because traumatic memories are 
complex and do not stay static. With this fluid and flexible form of sequential art, life writers can make the past, present, and future visible at the same time in the frames, gutters, and in multiple scenes juxtaposed together. Sequential art provides them a platform where they can jump freely from one memory to another representing the shape of trauma that often involves flashbacks and obsessive recounting of memories. For the moments for which they cannot attempt to express their emotional heaviness, the life writers can simply disappear in the alternative space of the gutters and let the audience actively participate in creating the narrative by filling in the gaps. In the next section of this thesis, I will analyze how the memories of childhood traumas in Lynda Barry’s One Hundred Demons and David Small’s Stitches get fragmented within the visual format of graphic narrative, and how the unique representation of time in sequential art enables the authors to effectively represent the shape of trauma.

\section{The Shape of Trauma}

Physical and mental progress are two of the prominent embodied subjects in Barry’s Demons as her life account is the stories of "girlhood" as Susan E. Kirtley explains it in her book, Lynda Barry: Girlhood Through the Looking Glass. The compelling part of these representations of Lynda's evolving body in her graphic memoir is their non-linear sequence. The image of Lynda that opens the narrative is that of Lynda as an adult; the cartoonist; the narrating "I." What follows this representation of self is the overlapping of her two memories during different stages in her life: the memory of falling in love with a boy during her visit to the Philippines as a child, and the memory of attaining head lice while being involved with her worst boyfriend. In the panels that stand side-by-side, there is more than one representation of Lynda's multiple selves without much verbal or visual transition provided by the narrator. On the visual 
surface of graphic narratives, the narrator can jump freely between memories without a solid textual structure to bind them. Without having to lead the audience to each site of storytelling with verbalization, the authors can simply bring the audience to the sites immediately, and multiple memories can stand side-by-side. This fluidity of graphic narratives become especially useful when unpacking one’s trauma. As previously stated, traumatic memories are complex and do not stay static. When the trauma victim recounts their memory and draws various interpretations of them each time, the memories get reshaped and re-illustrated as their viewpoint transforms over time. As the trauma victim interpret their traumatic memories, certain parts may get cut out, and others added in order for them to cope with the memories that inflict pain and unpleasantness and live on. In a way, one’s memory is one's narrative, one's story, and history. History is crucially decided by the one who gets to tell the story, and thus memory’s narrative- like structure is inevitably inherent.

The unique representation of time that sequential art provides is seen particularly useful when Barry brings up the subject of her abusive mother in Demons. As analyzed in the first chapter, Barry’s memoir requires a commitment of "unpacking” on the audience's end since her pleasant-looking artistic representation and the serious content of her subjects do not necessarily synchronize at all times. Buried beneath Barry’s vibrant and garish artworks is the dark subjects of domestic violence and abuse. For example, the physical and psychological violence that Lynda receives from her mother appears as early as the first chapter. While unpacking the memory of catching head lice as a child, Barry recounts, "When I mentioned the thing about the holy virgin to my mother, she slapped me” (18), followed by the images of Lynda's mother slapping Lynda and yelling "You Idiots!” (19) to her and her relatives. The representations ofthe mother’s violence and abuse (verbal and physical) consistently appear throughout Barry’s memoir and even appears in the form of her worst boyfriend (24). Under the surface ofBarry’s 
pleasantly colorful conventions of comics, Barry's violent mother moves in and out of her memories throughout most chapters like flashbacks of a trauma. Barry's mother is not a central figure in Demons since Barry does not directly discusses her mother in depth in any chapter she provides. However, Barry's mother definitely is a significant figure in Lynda's life nonetheless. Barry positions her mother, like a trauma itself that keeps coming back to her again and again, like flashbacks and a demon that haunts her, instead of telling the stories of her mother as a focused subject in her life narrative. Trauma often involves obsessive recounting of memories as the victim strives to recover from the traumatic wounds they gained from life events. Because of the unique format of sequential art that enables fluidity and flexibility in representing narratives, Barry can effectively summon the significant demon of her memories, the violent mother, that constantly haunts her life in the aftermath; constantly recurring in different sites of her storytelling as traumatic flashbacks. Without the fluidity in time in graphic narratives, verbalizing the abuse of Lynda's mother would have been a vastly different and difficult task, especially because Barry does not explicitly discuss the subject of her mother and the abuse she received, in her comics or out in public. She rather avoids directly talking about the subject of her mother. As I previously referred to in chapter one, Barry refused to talk about her mother when the interviewer, Dan Kois, requested her to discuss the subject of her mother. It indicates clearly that talking about her mother inflicts negative emotions to Barry, given that their relationship was not represented as a healthy one in Demons. Instead of verbalizing the abuse she received from her mother or focusing on the subject of abuse in a direct way, Barry illustratesthe moments of abuse in recurring fragmentation that shows internalized agonies of family dynamics in her memoir. The sequential art and its unique representation of fragmented time provides Barry a platform in which she can illustrate her mother in a fragmented but effective way. 
The fluidity of sequential art is also immensely utilized in Stitches to create a unique narrative pattern and represent the shape of trauma. In Small's Stitches, fear and dream are two prominent subjects on which he often ruminates in his narrative. In the narrative, the common ground for David's fear and dream is that they were both formed while David was growing up and around the traumatic events he experienced as a child. These include the growth on his neck, surgeries, losing of his vocal cords, and his family's abuse and their concealment and revealing of truths. Even after he experienced these events, his fears and dreams repeatedly haunt David as he matures. These haunting fears and dreams are inserted in the narrative in a variety of places in David's life without the narrator prefacing it for the audience.

One of David's fear that is consistently represented throughout the memoir is that of the fetus that he encounters in the hallway of the hospital where his father worked. He first sees the fetuses displayed in glass jars in the hospital. When David first sees the fetuses, he sees one of them being animated and meeting David's frightened gaze (39). As David runs away from the display, the following sequence shows the fetus come out of the jar, jump off the display shelf and run down the hallway towards terrified young David. The fascinating element of the visual representation in this scene is Small's unique use of frames and gutters. When the images of the fetus's eerie animation and escape are presented, the frames that act as the containers of the scenes completely disappear. As the fetus opens its eyes, stares at David, and escapes the jar (3940), the images are all free-floating without being contained by frames. Small seems to indicate that these are not solid memories that can be contained in the strict format of frames. Instead, they are illusive and fictional: they exist outside of the frames and thus beyond the factuality of David's experience and memory. In a way, the images of the animated fetus are found in an expanded space of gutters. The images are not inside the frame, which means that they belong in 
the gutter, that is wider than the conventional sizes in comics form. As McCloud argues, the gutter is a place where the audience actively participates to work out what is not shown in the scenes in the frame; that is, the transitions of events. In Small's Stitches, what is not shown-or "not supposed to” be shown because they are fictional memories of Small—is rather protruded and expanded. Small actively and consciously breaks the boundaries of reality and fictionality and acknowledges the fallacy of memories by subverting the convention of frames and gutters. As he expands the gutters and uses this space to integrate fictionality in his narrative, his narrative becomes more complicated. The audience now not only needs to actively participate in the narrative to witness what is presented and not presented to them, but also they need to reach farther. They need to actively engage with the fictional element in Small’s autobiographical account of life and cross the boundaries in their notions of fictionality in life narrative by interpreting and analyzing what these fictional elements actually symbolize and signify in Small's life.

In the next scenes that involve the fetus, the breaking of the boundaries between the real and the imaginary continues as the fetus starts chasing after David in the hallway. In these scenes, Small uses certain frames to contain the images but they are a different kind. The frame that contains the images of the fetus now is rather blurry, round, and unruly compared to the frames that he draws with more definite and strictly square-shaped lines. The interesting aspect of this representation is a synchronization of two images that achieve specific effect/affect forthe narrative. The image of David running in the hallway is situated on the top, in the middle panel (40). What the viewer can see is David's body movement_running with his head facing towards the floor, with his right arm raised-and the pattern of the ceiling in the hospital hallway. In the almost exactly same position of the middle panel on the bottom, the image of fetus chasing after 
David is presented in an uncanny way. The same pattern of the ceiling is presented, and more eerily, the bodily movement of the fetus stunningly matches the one of David on the top: running with its head facing towards the floor, and the right arm raised as it runs.

This uncanny synchronization of the two are not coincidental. The traumatic and illusive memory of the animated fetus haunts David in later moments of his life. After finding out about the growth on his neck, David examines himself in the mirror (146). When he looks at the growth on his neck, the image of the fetus appears in progression and becomes vividly visible on his neck as if it is growing inside of him (147). Why does the fetus inflict fear and haunt David so obsessively? Why does the image of the fetus synchronize with David as they both run in the hallway, creating uncanniness? Why is the fetus situated on his neck as an embodied entity when David examines himself?

For this compellingly powerful narrative device that Small utilizes, it is helpful to consider the concept of uncanny to understand the symbolization of the fetus. According to Nicholas Royle, uncanny is a crisis of the natural, touching upon everything that one might have thought was 'part of nature': one’s own nature, human nature, the nature of reality and the world. But the uncanny is not simply an experience of strangeness or alienation. It can take the form of something familiar unexpectedly arising in a strange and unfamiliar context, or of something strange and unfamiliar unexpectedly arising in a familiar context. (1) The core of uncanny is at the coalition of the familiar and the unfamiliar. The two elements need to be both present for one to experience uncanniness; the eerie feeling that something familiar has gone only slightly astray. In Small's case, the eerie feeling of uncanny presented by the fetus in the jar is originated by the growth that it represents. There is something about the "unfamiliar" 
fetus that is felt "familiar" to David, and that is the growth on his neck that he develops. Psychoanalytically, the fetus symbolizes the growth on David's neck.

A fetus symbolizes the concept of growth itself. Whereas a baby is considered an entity matured enough to be born, a fetus is yet in the process of growing before becoming an entity. If the fetus is out of a mother's womb before being ready to be born, the growth is stopped before becoming an entity. For the fetus in the jar that David encounters in the hospital, the fetus was “taken apart” from the mother’s body before it completed its growth progress and was contained in the jar. The umbilical cord that sustain its life and growth is "cut off.” The representation of David's fear of the fetus suggests something bigger than it is seen to represent on the surface. For these scenes, the audience must actively engage with the fictionality in order to understand the symbolizations that Small is making. David's fear is less about the fetus itself than about the growing lump on his neck. Not only that, it is cutting of the lump and losing a part of his body; the part of his vocal cord that gets taken apart from his body as the growth is removed. While David is seen being haunted by the fetus either by chasing him in the hallway or appearing eerily in the reflection of him in the mirror, what Small symbolizes in these scenes is his fear of his growth on his neck and its traumatic removal that is forthcoming. The narrating "I" in this case is present in all spaces in time. While narrating the past, the narrating "I" is aware of what is going to happen in the future. Young David, the narrated "I”, is seen unaware of what is happening to his body, but the narrating "I" does. With the platform of sequential art, Small creates a narrative space where the past and future coexist at the same time. By inserting the symbolization of the fetus in the moments before the diagnosis, Small illustrates his true fear of his growth and removal and signal something significant to come in the narrative. 
The symbolization of the fetus and growth connected to his embodiment can be further expanded on page 135 where David leaves the hospital after he gets his first check-up for his growth. As David leaves the doctor's office, a full-bleed image of the hallway mirrors with two shiny surfaces is presented. On the shiny surface of the mirror, David and his mother are reflected on the left side (135), with the same representation of the hallway that appeared when David was being chased by the fetus (40). On the right side, the flipped image of the hallway is presented in, again, an uncanny way. The hallway reflected on the right is juxtaposed in exactly the same design as the left, only it is unoccupied on the right. While the fetus was synchronized and juxtaposed with David in the chasing scene that appeared previously in the same hallway (40), this time, as David leaves the doctor's office, the fetus is gone. Nothing is there on the juxtaposed scene, symbolizing the upcoming removal of the growth that David will experience along with losing his vocal cords.

Finally, the image of the fetus appears for the last time when David as an adult visits his dying mother. He faces his fear as he looks at the fetus in the jar in the hallway. The images of the fetus are now contained in the solid frames and left unmoving, and unanimated, reflecting David's mental progress of overcoming his fear, the fetus that symbolizes the traumatic removal of his body part.

Similar to Barry's Demons and her representation of her mother, David's fear goes in and out of the narrative in a fluid and flexible way as well. The way that the fear of fetus is represented in resembles flashbacks. The fetus in the jar haunts David, appearing in his life repeatedly like the memory of his trauma in different stages, constantly transforming. Because of the format of sequential art that integrate a representation of non-linear time, Small does not need to provide verbal cues while representing this symbolic art that resembles trauma. His fear comes 
in and out of the narrative like an uninvited visitor. The unexpectedness, unpleasantness, and unstoppable force of the repetitive memories of trauma are effectively/affectively represented through the symbolic illustrations of the fetus.

David's recurring dream is also a significant narrative subject in Stitches and it is also illustrated in a similar manner to the symbolization of the fetus. In Small's memoir, the representations of the fetus were often followed by events that were emotionally vexing. David's recurring dream of the cathedral with small doors and the ruins also often haunts him after emotional episodes he experiences.

In the recurring dream, David enters a temple and goes inside the small door that leads to a succession of rooms, narrowing hallways, and even smaller doors as if he fell down the rabbit hole in Lewis Carroll's Alice's Adventures in Wonderland, only to find out that what's waiting for him is not the odd creatures or the Queen of Hearts playing croquet. Instead, it is the mound of ruined parts of the temple, or the seeing of the temple "whose guts had been bombed" (242). This recurring dream often haunts him after emotional moments. In one occasion, it happens after David experiences an emotional breakdown in relation to losing his vocal cords. He described, “At home, late at night, I began to have the sensation that I was shrinking down... and living inside my own mouth” (216). David was being immersed by the traumatic memory of losing part of his body in his throat, and the recurring dream follows this memory. In another incident, when David confronts his parents about the cancer diagnosis, David's parents tell him that he didn't need to know anything about his own cancer. Then, the recurring dreams haunts David again. Like his fear of the fetus, the dreams are also juxtaposed with memories that are emotionally painful for David, haunting him incessantly as flashbacks of traumatic memories. Even some of the images of the dream are exactly copied and used more than once in the 
narrative. The temple that he constantly explores, like Alice, in his dreamland is also a symbolic representation of his trauma like the fetus. Until the very end of the memoir, the memories of the haunting dreams (also represented without frames to indicate the fictionality of dreams) are mostly provided without any context or analysis. The memories simply show up, abruptly inserted in moments. However, a brief reflection for his dream is provided at the end of the memoir. In the dream, David is again in a big and tall building. Instead of going through the narrowing hallways and finding the ruins of the temple, David, as a boy of six, looks outside the window. In the building across from him that resembles the temple of David's dreams is in fact, the asylum. David's mother and grandmother are sweeping the path and clearing the way for David. This building would embody the ruin in its center that David constantly finds in his recurring flashback-like dreams; the ruins of his family; the violence that his family member inflicted upon David as he grew up. As Small suggested, by overcoming his fear he was able to stabilize his trauma; there's a progress in his mentality by looking at the unanimated fetus (309). His final dream also indicates a progress in overcoming another trauma that runs deep within his family members. He is in a different physical space with his family. He looks at them in the distance and the building in which he is positioned is more neatly organized with sophisticated objects in contrast to the ruin of the temple or the asylum. With his finally statement of "I didn't" (325), Small suggests that David overcomes the trauma of his family and find a different psychological path in the future that he pursues.

In both Barry and Small's graphic memoirs, the sequential art enables them to create unique representations of time where the shape of trauma is distinctly illustrated. Through this platform, the authors are able to keep circling back to their traumatic pasts as the victims of the traumas often do. Lynda's mother haunts her by appearing in several sites of Barry's 
autobiographical stories of childhood and shows the psychological and physical pain that she caused Lynda, while Barry does not directly address her importance in the text. Small's rather symbolic representations of his fear and dream are tied to his traumas: losing a part of his body and the abuse received by his family. In both Barry and Small’s cases, the memories keep coming back to the narrative like a broken record of the authors' traumatic experiences in their childhood. With their use of sequential art, these traumatic memories and the recurring symbolizations of distinct subjects are illustrated in a way that strikingly resembles the shape of trauma: recurring, haunting, obsessive, and most importantly, unfolding. In Small's case, there is a distinct sense of overcoming his own traumatic memories of his surgery and family that allows to see his narrative as a nonfiction bildungsroman, a coming-of-age story. David grows up to be an independent and functioning adult who finds his place in an artist community. He no longer sees the fetus animated in the hospital hallway, and he asserts that he did not follow the paths that were ushered by his mother and grandmother.

Barry's case is a bit different. Barry ends her narrative with Lynda's growing affinity for making comics and finding a medium where she can tell her stories. She does not give a definite ending to her conflicts or traumas. Instead, Barry provides an alternative ending that illuminates the subject of art-making, followed by the do-it-yourself page for the audience. In a similar way to Small, Barry finds her peace in artmaking. In that sense, both Small and Barry's life narratives are künstlerroman (a narrative about maturing into becoming an artist) as well as bildungsroman. In both narratives, the traumatic memories are central to their developments as functioning adults and artists. Because of the haunting memories of trauma that constantly circle them back to their pasts, they look for a medium to illustrate those haunting memories. With sequential art, both authors illustrate their traumas in the shape that haunts them; capture them in the frames to be 
grounded in the safe place of the medium of comics where the memories stay as narratives rather than demons.

\section{Narratives of Childhood Trauma and the Fallacy of Memories}

In Contesting Childhood: Autobiography, Trauma, and Memory, Kate Douglas examines a plethora of auto/biographies produced in the 1990s and 2000s and claims that childhood is a subject that gained exceptional popularity and momentum during that time of the memoir boom and notes that the subject of childhood trauma often appears in those memoirs. Douglas states, The most notable and perhaps the most infamous publishing trend of the 1990s was the autobiography of childhood - a piece of autobiographical writing concerned with the narration of childhood experiences. Autobiographers ... burst onto the American literary scene in the mid 1990s, paving the way for a plethora of similarly styled texts to follow. These autobiographies were distinctive for their depiction of challenging, often traumatic childhoods—characterized by abuse, poverty, discrimination, and identity struggles. (1)

Both Barry and Small's narratives center on traumatic childhoods involving abuse and identity struggles caused by the unhealthy and violent family relationships. There is a sense of being lost and recklessness in Lynda's adolescence and girlhood, heightened by signs of depression and drug use. Lynda receives verbal and physical abuse from her mother as the audience can see her constantly coming back to the Barry's memories, and the implication of the sexual assault Lynda experiences as a child is equally strong as I suggested in chapter one. Small's narrative delves into the subject of abuse and identity struggles rather directly and in an affective way. With the grayish-looking watercolor artistic style that casts shadows over Small’s memories, Small demonstrates how David is received as an objectified entity by his family. To his family, his will, 
emotions, and right to know about his illness are what need to be silenced. His being is merely a thing to be treated and controlled by his family members. Even before losing a part of his vocal cords, David is silenced by his family. He wants to scream to his family as the images of David's multiple overlapped screaming faces suggest (234), but his voice has never really been heard by his family. Ironically, it is after David loses his vocal cords that he begins to be heard. When he breaks off from his family and finds himself belonging to an art community, David starts to be recognized as an individual with good taste and agency (in contrast to his childhood where he was constantly objectified and silenced). David shows a glimmer of joy in his face, and people compliment him by saying “Hey! You are really good!”, looking at his art, and “Cool neck scarf!” pointing at his outfit (302). Along with what happens in Barry’s narrative, the traumatic abuse David receives and overcomes to establish self-identity is deeply correlated. Both narratives successfully reveal the connection between the two subjects via affective visual art. However, Kate Douglas points at criticism received by the autobiographies that dealt with childhood trauma during the memoir boom. She argues,

The association between autobiography and childhood trauma has brought the genre both acclaim and infamy. At best, autobiographies of childhood have been praised for bringing child abuse to public attention and becoming tools for advocacy; at worst, these books have been criticized for being exploitative, unethical, and even voyeuristic in their representation of child subjects. (3)

Douglas explains that many autobiographies dealing with childhood trauma gained attention as the socio-cultural interest in the child figure emerged in culture and these autobiographies were often criticized for sensationalism and being exploitative. Furthermore, the subject of childhood trauma was disturbing to many readers since these autobiographies "have commonly placed the family under intense scrutiny" (5) because "[w]hen child abuse occurs, the most common site is 
the family” (5). As much as these autobiographies advocate for trauma victims, the characters of these accounts are not fictional even though their names might have been changed. People in real life are involved in the accounts that the trauma victims often engage when writing shocking stories of abuse and trauma.

The ethics of life narratives that deal with childhood trauma get even more complicated when the subject of memory emerges. Memory has become a popular and influential academic field and Nigel C. Hunt suggests,

Memory is now the focus of interest to people across a range of academic disciplines, far more than it was a few decades ago. It is no longer the sole remit of psychology. ... The new journal Memory Studies explicitly states that it is a journal that hopes to draw on a wide range of disciplines, and help academics to develop and present theories that are interdisciplinary in nature.... This interaction has to be a good thing, broadening our understanding of memory, outside the normal remit of a narrow academic discipline. (98) As Hunt illuminates, the study of memory has become the focus of many scholarly discussions, and a variety of disciplines such as sociology, history, anthropology and political science have played key roles in understanding the conceptualization of memories. Marianne Hirsch also echoes this idea with her compelling research on postmemory. Understanding the concept of postmemory, which draws the relationship of the second generation to traumatic experiences of the generations that preceded them, relies heavily on history and the life writings by the second generation of the Holocaust survivors such as those exemplified by Art Spiegelman's Maus. Hirsch states that “'memory studies' as a field of inquiry have grown exponentially inacademic and popular importance in the last decade and a half" ("The Generation.” 105). What these scholars' statements signal is the necessary involvement of different scholarly disciplines in 
unpacking the concept of memory and the complexity and plasticity of memory that require our deeper cultural understanding.

Memory plays a significant role in life writing. As Douglas claims, "Memory drives autobiography, and in turn, autobiographies influence perceptions of the ways in which memory functions” (21). It is not only the writers of autobiographies that engages with the concept of memory in a significant level, but also we, as readers, conceptualize the notion of memory with the use of autobiographies that powerfully influence our culture. However, the complexity and plasticity of memory have always been crucial subjects among scholars in the discussion of autobiographies that deal with trauma. The questions such as: How do adults remember their childhood? Who has the authority or the rights to tell the stories? What kind of disclosures are culturally acceptable and not? How reliable are our memories? arose as the critical debates over trauma stories gained attention. To elucidate how heated the critical debate on trauma stories have gotten, Douglas explains the "false memory syndrome" that arose in the 1990s with the memoir boom.

For example, the "false memory syndrome" movement, which arose during the 1990s, warns against the fabrication or exaggeration of child abuse narratives—offering protection to parents who have been falsely accused of abuse by their children (who are now adults). There are obviously serious consequences for parents who are falsely accused of child abuse — particularly emotional hardship, and financial hardship if litigation ensues. False memory syndrome focuses on the fragility of repressed and recovered memories (Loftus and Ketcham; Ofshe and Watters) (108). 
As Douglas argues, there are many complex issues involved in telling stories of one's traumain autobiographies of a trauma victim. Hunt also echoes Douglas's view on the fragility of repressed and recovered memories of trauma by stating,

While we integrate our normal life memories into our life narrative, traumatic memories are not so integrated. Traumatic memories are dominated by sensory, perceptual and emotional components, components which are harder to integrate into the conscious narrative as they do not normally have verbal components. This means that they will have fewer interconnections and weaker organisation. (O’Kearney and Perrott, 2006) ... The experience of trauma disrupts the creation of the life story, creating an incoherent, disorganised and fragmented narrative. This special nature of traumatic memory makes integration problematic for many people, but integration—it is argued—is vital for coherence and, in turn, reconciliation. (119-128)

As Douglas suggests by describing traumatic memories as "repressed" and "recovered," Hunt's statement also reveals that the memories involving trauma are often unstable and incoherent. Concerning collective memories of the Holocaust, Hirsch also suggests that "even the most intimate familial knowledge of the past is 'mediated' by broadly available public images and narratives," ("The Generation.” 112) noting at the powerful cultural and societal impacts on our memory-making process. Hirsch’s argument further applies further to personal memories of family trauma. Personal traumas are also shaped and mediated by the victim's processing of the traumatic memories, therapies, interventions of their family members as to what they should remember or not, the family's each individual account of the same memories, and cultural forces at stake. There are "personal factors (importance of event, distance in time, illness and disease, narrative) and social factors (social and cultural discourses, interactions with other people) which 
impact on what we remember" (Hunt, 118) and we understand that memory is complex and plastic. These various factors are easily applicable to both Barry and Small's accounts of childhood traumas. As much as their life narratives reveal the atrocities they experienced from the adults around them while growing up, readers can also see that their memories are mediated by many factors that Hunt compellingly addresses. Understanding the complexity of memory in autobiographies of childhood traumas at stake, what do readers make from these trauma stories that involve serious accusations of the adults who inflicted trauma and pain to the narrators? How stable and reliable are the truths they are representing? How much do readers believe and how much do we not? How do we conceive and accept these complex stories?

\section{Fictionality and the Ethics of Life Narrative}

Trauma stories are much needed narratives in our culture. Leigh Gilmore suggests, "language is pressed forward as that which can heal the survivor of trauma" (6). As examined in the previous chapters, the telling of their traumatic life stories through the platform that utilize visual art offers healing experiences for both Barry and Small, and even plays an active role in overcoming their traumas. Furthermore, trauma stories also "have been instrumental in breaking silences and creating cultural templates for stories to be told (Douglas, 107). Douglas claims that the autobiographies that deal with childhood trauma significantly impact our cultural conceptualizations of children and childhood.

These texts are deeply imbued with the preoccupations of the present—children's rights, futures, education, violence against and by children, socialization, and childhood sexuality, to name just a few pertinent examples. Individual lives become emblematic of wider social concerns about childhood. I consider autobiographies of childhood as tools 
of cultural memory. ... I consider the ways in which autobiographies of childhood function to both "corrupt" and "protect" childhood. (6-7)

As Douglas illuminates, individual memories and personal accounts of one's childhood are deeply related to our cultural and political conceptualization of children. Life writers constantly bring significant subjects that may "corrupt” or "protect” the way we understand children and childhood. Authors such as Barry and Small provide complex stories to complicate and challenge the way we view children and childhood with their authentic life accounts. These accounts reveal often silenced subjects of child abuse, sexual assaults, and trauma, and bring these subjects into cultural discussions and debates. They also shed light on the complexity of understanding these stories. These memories that involve trauma are complex, unstable, and mediated by different individual and socio-cultural spheres. Hunt notes that the narrative account involving trauma is “fragmented, disorganised and contain gaps” (128). Discussing the ethics of life narratives in such a case becomes difficult since each life writer's account stands as an authentic narrative of their own life, and truth gets complicated to be defined. There can be more than a single truth and this is an ethically complex issue when it comes to accounts of abuse, assaults, violence, and so on. Because of this aspect, the life writers' ability and willingness to acknowledge the difficulty in the ethics are significant to help our understanding of trauma. However, here are autobiographies that especially fail to bring organic conversations of trauma and recognize its pitfalls. These accounts do not acknowledge critical conversations on the ethics of life narratives. Douglas offers a compelling criticism on these narratives and sheds light on the importance of extending the conversations on the ethics of life writing.

And yet survivor testimony that fails to consider ... the complexities of narration surely does very little to enhance our understanding of traumatic experience or to further the 
cause of traumatic life writing. This is not to suggest that traumatic autobiographies of childhood must offer balanced treatments of parents, guardians, and other relational subjects—rather that these trauma texts should demonstrate some overt consciousness of ethics, and of the autobiographies as relational ... there are many ways in which autobiographies of childhood accomplish this—-for instance, through assertions that this narrative is subjective and that the memories it contains are fragmented. Such acknowledgements greatly extend autobiographies ongoing critical conversations on subjectivity and the ethics of life writing. (149)

What Douglas is attempting to elucidate in this statement is not the fallacy of the victim's memories and testimonies. Rather, what is pressing in this discussion, is the necessity of the life narrator's demonstrated understanding in the complexity of the account that they are creating and the consequences that might bring. As we continue the debate on the questions of "Who is telling the truth?" and "How reliable is one’s memory?" when it comes to traumatic life accounts, we may not come to a definitive end in the discussion or a clear answer for such questions. What is at stake here is how these authors of traumatic life stories present their stories in an authentic way while acknowledging their subjectivity in the discussion of their memories that will enable and extend the critical conversation on the ethics of life writing, especially for the ones that involve traumatic life stories such as Barry and Small's accounts.

To acknowledge the complexity of trauma stories and provide authentic accounts, life writers may utilize fictionality, and Barry and Small's life narratives effectively do so in two distinctly different ways. Barry consciously and directly brings up the question of subjectivity, fictionality, and authenticity of life writing in her memoir: She asks, "Is it autobiography if parts of it are not true? Is it fiction if parts of it are? (7). Instead of giving answers to these questions, 
she implies that painting her demons is her active practice to unravel her complicated "demonlike," living memories that may change their shapes and influence the narrator as she tells her story. Furthermore, she labels her graphic memoir as "autobifictionalography" on the table of contents page (5). Her questions about the fallacy of memories and the alternative categorization that she gives to her own memoir assert that her narrative is subjective, and reveal that memories are fragmented. Yet, by giving up her authority as the teller of the truth, her narrative becomes more authentic, breaks free from accusations, and opens a new avenue for understanding trauma stories. Discussing accounts of war trauma, Hunt notes that veterans "must have an audience to provide support for the processing of traumatic memories, which leads to reconciliation" and claims that "The necessity for an audience to understand the story has implication for identity, problem solving and sharing” (129). With the author's acknowledgement of the account's subjectivity, a trauma story extends further than a mere testimony. It becomes a place where the author reconciles with their own past, and a place for the audience to conceptualize memory and identity in a way that helps form new cultural and societal understandings of such subjects as a community.

As Barry brings fictionality into the discussion of her autobiographical account, Small also uses fictionality. However, his method is different from Barry's. As I analyzed in the previous section, Small subverts the traditional use of sequential art in compelling and symbolic ways, transforming the conventional shapes of the frames and gutters of comics so that his narrative can expand further than the rigid space of reality. In the alternative space of gutter where our imagination belongs, he inserts memories that may or may not be real. He further breaks the boundary between reality and imagination by playing with the frames; blurring the lines and bending their conventional shapes that break the boundaries between frames and 
gutters. The subversions of the sequential art's conventions point at the slippery slopes between one’s memory and mediations. His images are also heavily overcast by shadows that hover over each character. Shadows are illusive. They mimic the shape of the objects in reality, but they never truly reflect them. Just like shadows that only bring shapes, a limited depiction to reality rather than accuracy, the memories represented in Small's memoir are also overcast by shadows that impact the way we conceive things. Thus, shadows are also a component that symbolizes subjectivity to his life account. Shadows float on the surface of Small's illustrated images like ghostly figures and give eerie atmosphere to the graphic memoir. This illusive and mimicking element of shadows suggests that his memory is subjective, heavily influenced by the way David perceives the world. As much as the lines between the frames and gutters are mediated by the authors' drawing of his memories and illusive shadows are cast over them, his life account that deals with his trauma is also mediated by many personal and social factors around the life writer. “Form follow function” is, again, an adequate maxim to apply to Small’s example here. On the subject of literary criticism about abuse narratives and its impact on mediation, Douglas argued, Rather than focus on the veracity of autobiographical writing, and make accusations about sensationalism, literary critics should focus more closely upon abuse narratives as cultural texts that link therapy and literature in important ways. Literature, like therapy, has become a powerful mediator of child abuse. (130)

As Douglas suggests, narrative that deals with heavy and controversial subjects such as abuse and trauma should not be understood merely as telling of the slanted truth. They should be understood as fragmented and subjective yet authentic stories that mediates in the process of healing an individual and furthermore describe collective and cultural pain of trauma that involves children. These authors bring compelling and provocative (or "shocking”) stories that 
needed to be culturally discussed. These stories are certainly necessary narratives that need more public attention along with children's rights and our conceptualization and understanding of complexity of childhood.

In “Affective Studies,” Sean Grattan stated that “the work of art exists simultaneously and separately from anyone experiencing it and whoever produced it” (335). The fictionality in life narratives can be further understood as an effect and affect that these two authors evoke. By using narrative strategies such as embodiment, materialities, and fictionality, Barry and Small create powerful effects and affects in their storytelling; and they both simultaneously and separately exist from their work of art. As much as they are the narrator of their life account who tells the factual history of their pasts, they are also, at the same time, protagonists in a narrative that they create with the elements of fictionality. This duality in the narrative voice and the concept of affect are significant in relation to the ethics of life writing because the dual voice allows the authors to exist in two different spaces: one of a trauma victims, and another of a separate entity who tells the story from outside viewpoint partially separated from the former. In chapter two, I discussed how the duality of graphic narrative enables Barry and Small to become the witness of their trauma through their art form that embody their traumas. By illustrating their own traumas that they experienced as children, they become the witness of the embodied memories of their own traumas. In a very similar way, the concept of affect also allows these authors to be understood as two separate entities. The common saying goes, "One must separate the art from the artists.” Yet, it is a little more complicated than that. The authors of life narratives, are, at the same time, the work of art that they created, and are not. As Grattan explained, "Affect theory is an attempt at getting at the heft, shape, and borders of feelings, and how those feelings ineluctably shape our political, cultural, and aesthetic experiences of the 
world" (333). Considering the concept of affect in life accounts that deal with traumatic childhoods can open a new avenue in conceptualizing the ethics of life writing. Understanding affect helps us understand that the concept of truth is neither static or absolute. The life accounts that the authors of traumatic stories are bringing in (often shocking, provocative, and involve many actual lives) are not necessarily a single standing truth that they are attempting to represent. The stories are the histories of the authors' lives but, at the same time, also are narratives that they are constructing. In this way, affect theory both gives authenticity and authority to life writers in the accounts that they present, and take authority away from onesingle life account in terms of the power dynamic that they may withhold over who gets to tell the story. Resisting to conceptualize life narratives as mere accounts of facts, affect theory allows these accounts to be something bigger than that. These accounts are what shape and influence our cultural understandings of the difficult subjects such as abuse, assaults, and violence by bringing compellingly effective/affective voices of those who were once silenced; the survivors of traumas and violence into the cultural and political discussions. Moreover, for the readers of traumatic life accounts, affect theory provides a frame to understand the authors' works of art in their heft, shape, and the emotions and impacts they evoke, and see how these elements construct our socio-political understandings of complex subjects in our culture such as domestic violence, abuse, assaults, and trauma. With innovative life writers like Barry and Small who actively brings fictionality into their account and subverts the conventions of their rhetoric, and compelling frames such as affect theory that help analyze complex ethical issues in life narratives, we understand better the complexity of these traumatic accounts of childhood. The memories of pasts that they ruminate on may be fragmented and fragile, the effects/affects that the authors of traumatic accounts invoke have powerful impacts in our culture. The voices that 
were once silenced are heard, the perspectives that were once put out of sight are now envisioned by these authors.

In this chapter, I ruminated on the subjects of time in sequential art, fallacy of memories, fictionality, and the ethics of life narratives. These elements are closely tied together in the accounts of traumatic memories as they bring complex subjects in socio-political discussions in our culture. First, the format of sequential art helps the life writers, Barry and Small, to depict their traumas in the shapes they experienced them. Certain memories of their pasts keep circling back to them as they process their traumas. This function of sequential art defies the rigid structure of verbalizing one's trauma and allows the authors to illustrate them in effective/affective ways in the shape of their traumas as Barry and Small demonstrated. Furthermore, it also contributes in integrating fictionality into the life account. As Small reflects on the memories of his dream and fear, the fictional elements in these ruminations brings symbolic interpretations on his traumatic life account shed light on the psychological process of his trauma.

Second, the fictionality in these accounts functions as an important mediator since it signals the authors' overt acknowledgements of the plasticity of one's memory and perspective. Barry's questions on the fictionality of life narratives, and Small's crossing the boundary between the real and the imaginary both actively acknowledge the subjectivity of their life accounts. As scholars I referred to in this chapter such as Hunt, Douglas, and Hirsch point out, memory has become an important and complex subject in various academic discussions. These authors' conscious acknowledgements of memory's complexity are vital because the authors are always engaging with the ethics of life narratives by telling the stories of their traumas and help the discussion of memory and ethics progress further. 
Finally, I argued that the ethics of life narratives can be further understood with the frame of affect. As the authors of the traumatic life accounts exist both as the works of art they created and separately from them, evoking profound effects/affects in the audience, we better understand the life narratives and their functions in the ethics. They are not merely factual histories of one's trauma, but also powerful narratives that impact the way we conceptualize traumas in our culture and bring silenced voices in the discussion.

In the following conclusion, I will take all my analyses on Barry and Small’s memoirs into account and explore how the two authors constantly cross boundaries of forms, narrations, and readerships. By doing so, I intend to help contribute in shedding light on the innovativeness of these two talented authors' graphic memoirs and the significance in examining the complexity of life narratives that integrate multimodality and multimedia. 


\section{CONCLUSION: CROSSING BOUNDARIES}

In my thesis, I examine One Hundred Demons by Lynda Barry and Stitches by David Small to see how the duality of graphic narrative impacts the way the two authors tell the stories of their childhood trauma. Both authors explore the common subjects of childhood, adolescence, trauma, and growing up to become an artist in the format of sequential art that enables them to showcase the painful memories of their childhood in their graphic memoirs. Chapter 1 examines the dual rhetoric of words and images, specifically how the two authors utilize silence and visual metaphors as strategic ways to visually display their traumatic memories without having to speak about the inexpressible subjects of their childhood. Chapter 2 examines the graphic embodiment to analyze how it allows the authors to become the witness of their own trauma through their visual storytelling, and how materiality helps them in the task of bringing back their private memories of childhood in a format that demands a private reading for the audience. Chapter 3 explores the ways in which the two authors utilize sequential art to display a unique structure of time that effectively carries out the task of showcasing the temporal shape of trauma while bringing fictionality to the discussion in the ethics of life writing.

In their memoirs, Barry and Small utilize sequential art to pursue the mutual goal of expressing the inexpressible memories of childhood trauma. Even though the two authors’ artistic styles are significantly different, the common ground for these two authors is that they both cross boundaries in variously innovative ways. First, they cross the boundaries of rhetoric by using words and images, allowing their storytelling to cross the limits of a single rhetoric. Second, the authors cross boundaries with dual narration of an adult narrator and a child/adolescent protagonist in their life narrative. This duality in narration poses a significant 
question in the ethics of life writing. If the narrator is adult, it signifies that a notable amount of time has passed and a change in perspectives/memories is expected to have made. Then how do readers see these authors as reliable storytellers of truths? In Telling Lies in Modern American Autobiography, Timothy Dow Adams acknowledges the difficulty in defining the truth/lie relationship in autobiographical writings. "Autobiographical theorists have qualified their call for truth so much that it is virtually impossible to test, and autobiographers now are said to pretend to believe their audiences think they are trying to tell the truth” (10). Adams concludes his statement by claiming, "The truth in autobiography—difficult to name, impossible to verify— can be better understood if we think of it as narrative rather than historical truth” (12). The two authors—Barry and Small—acknowledge this impossibility in verifying the absolute truth in their memoir by breaking the boundaries of their narration. For Small, it’s blurring the lines between memory and imagination in the frames and gutters. Instead of containing his memories in a rigid form of conventional cartoon panels, Small lets his memories explore the spaces of both fiction and nonfiction through the flexible lines between the panels and gutters in his graphic memoir. Certain memories are contained in the rigid frame and seen as realistic, but certain memories are set out in the gutters and often seem unrealistic. By bringing both elements to his memoir, he situates fictionality in his storytelling. For Barry, situating fictionality and acknowledging the difficulty in defining truths is more direct. She defines her memoirs as "autobifictionalography" which signals that her memoir is an authentic narrative rather than a truthful history of her life.

Last, by having dual narration, the two memoirs refuse to be defined or categorized merely as books with a single target audience. In an article about Small's memoir, Stitches, 
Leigh Gilmore and Elizabeth Marshall explain how controversial the book became around the time that it was getting nominated for various book awards. Gilmore and Marshall claim, Stitches was a controversial National Book Award finalist in the young people'sliterature category. The placement of Small's graphic memoir in this category rather than in the adult category sparked disagreements around the book’s appropriateness for a YA audience. ... When W. W. Norton (also the publisher of graphic novelists R. Crumb and Will Eisner) nominated Stitches in the young people’s literature category rather than nonfiction adult, it entered an ongoing debate about the limits of knowledge, agency, and youth that plays out in conflicts over genres, audiences, markets, and texts. ... its status as a nonfictional trauma narrative caused many people to challenge the decision. ... While YA literature characteristically covers disturbing topics related to coming-of-age, .... Stitches' status as nonfiction, and thereby Small's claim to represent his actual experience, rendered this graphic memoir unacceptable. (17)

Gilmore and Marshall explain how W.W. Norton defended "the book's placement based on market research about who was reading Stitches" and claimed that Stitches has been a crossover book (17) when they received much criticism. This controversy around Small's Stitches calls attention to the longstanding debate on the definitions of Young Adult literature. Small's Stitches, along with Barry's Demons, is indeed, a coming-of-age story. Roberta Seelinger Trites notes coming-of-age narrative as one of the origins of YA literature. Coming-of-age narrative, or in German term, bildungsroman, is a narrative "in which the protagonist comes of age as an adult” (Trites,10). Concerning bildungsroman, Trites further explains,

The concept of the Bildungsroman emerged in an atmosphere nurtured by the romantic belief in the individual. ... the protagonist's growth is neither accidental ... nor simply a 
matter of normal developmental growth, ... rather, the hero self-consciously sets out on a quest to achieve independence. The Bildungsroman is therefore an inherently Romantic genre, with its optimistic ending that affirms the protagonist's entry into adulthood. (1112)

Unlike entwicklungsroman which is purely a novel of development, in bildungsroman the protagonist autonomously seeks out independence and achieves it at the end of the narrative. Trites also notes the limits of the genre of bildungsroman by introducing the ideas of scholars who critiqued the genre for being majorly androcentric. In Archetypal Patterns in Women's Fiction, Annis Pratt claims,

In the woman's novel of development (exclusive of the science fiction genre), however, the hero does not choose a life to one side of society after conscious deliberation on the subject; rather, she is radically alienated by gender-role norms from the very outset. Thus, although the authors attempt to accommodate their heroes’ Bildung, or development, to the general pattern of the genre, the disjunctions that we have noted inevitably make the woman's initiation less a self-determined progression towards maturity than a regression from full participation in adult life. (36)

Pratt further claims that it would be appropriate to position women's narrative rather as entwicklungsroman since the genre is a novel of development (instead of bildungsroman that hints at the protagonist's coming-of-age as an autonomous and independent individual). In In $a$ Different Voice (1982), Carol Gilligan challenges the conventional notion of autonomy and independence that are majorly understood in the perspective of the psychological and moral developments of men, resulting in limited understandings of concepts such as autonomy and 
independence. The moral values of such as are often defined by the standards of men's moral development and exclude the one of women. Gilligan asserts,

Against the background of the psychological descriptions of identity and moral development which I had read and taught for a number of years, the women's voices sounded distinct. It was then that I began to notice the recurrent problems in interpreting women's development and to connect these problems to the repeated exclusion of women from the critical theory-building studies of psychological research. ... The disparity between women's experience and the representation of human development, noted throughout the psychological literature, has generally been seen to signify a problem in women's development. Instead, the failure of women to fit existing models of human growth may point to a problem in the representation, a limitation in the conception of human condition, an omission of certain truths about life. (1-2)

Gilligan's assertion about the exclusion of women's development and the limitation in conceptualizing human condition connects well to the limited representations of bildungsroman. Bildungsroman has been heavily understood as the development of moral values in men's lives. Viewing and framing bildungsroman only with the traditional and androcentric notions of autonomy and independence would limit the understanding of certain narratives of development. As Pratt argues, the protagonist is considered to achieve a self-determined progression in the traditional bildungsroman. However, not every coming-of-age narrative ends with the protagonist's achievements as an autonomous and independent individual in an androcentric sense. But it doesn't mean that those alternative narratives are not about development. Usually women writers provide alternative visions of development that reach outside the conventional androcentric moral development, or the conventions of bildungsroman that are rooted in 
romanticism. Barry's Demons and Small's Stitches definitely demonstrate the distinction between a male and female bildungsroman with their very different accounts that embody common subjects. In Small's narrative, David claims autonomy and independence as an adult and budding artist, and the way he achieves these values are notable since his path distinctly follows the traditional model of bildungsroman. During the journey of David's growing-up, the audience of the narrative do not see any help given to him from others around him. His parents, grandparents, and schoolmates do not offer any emotional connection or assistance for Davidand even his therapist seems to be only a catalyst figure who presents him with a cold and harsh truth when David weeps on the floor, holding his therapists' legs (Small, 258). It is only when David makes accomplishments by getting involved in the artists' circle that he receives positive human connection from others. However, even this moment is framed to celebrate David's accomplishments as an adult and an artist as others compliment his taste in clothing and artwork (Small, 302). David, as a protagonist, is a completely disconnected, autonomous individual and this is framed as an achievement and a progress for him. However, the central conflict in this narrative—David's struggle in connecting to others around him—is still somewhat left as unresolved or at least questionable. It is not entirely clear if David achieves a caring, compassionate, and positive relationship with others around him at the end of this narrative.

On the other hand, it is clear that Barry does not follow the conventional narrative pattern of bildungsroman. Demons does not end in a way that celebrates Lynda's autonomy, independence, and success as an individual like Small's narrative does. Unlike Small's memoir that was originally published as a book-length work, Barry's Demons was originally a web comics series and later published as a one-volume collection. Perhaps because of such a publication style, Barry's narrative does not reach a decisive endnote that celebrates Lynda's 
accomplishments as an adult and artist. Yet, Barry's Demons, nonetheless, seems to suggest an alternative conceptualization of coming-of-age narrative with its ending. At the end of her narrative, Barry presents the chapter, "Lost and Found.” This chapter does not provide a representation of growth as an individual or successful claiming of autonomy and independence in the traditional sense of bildungsroman as Small's narrative does. Alternatively, Barry's "Lost and Found” suggests emotional connections through consuming and creating narratives as a solution to dealing with hardships and isolations. When young Lynda reads through the lost and found sections of newspapers, she finds comforts in imagining "the freaked-out people, the freaked-out animals, and me, always coming to the rescue and never accepting the reward” (Barry, 209). As Lynda builds her imaginative narratives in her head while reading the lost and found sections and classified stories of newspapers, she is emotionally invested in the stories as she daydreams about finding the lost animals and shedding tears over classified stories of tragic endings (Barry, 211). These classified stories, one might argue, are a form of life writing since not only the narratives of actual lives are presented through writing in the newspaper, but also inherently touches on other people's' lives as young Lynda demonstrated with her emotional investments in these life stories. The memories of reading these classified stories-life writingremains with Lynda through her adolescence and adulthood as the subject of emotional connections through narratives continues to be unpacked throughout the chapter. Through the ruminations on classified stories, Barry provides a compelling comment on narratives and their healing power. The narratives in newspapers that Lynda engages with provide a sense of human connection and comfort while she struggles to connect with others around her in reality through the years of her growing up. Instead of presenting Lynda to come of age as an individual who achieves development by presenting the traditional notions of autonomy, Barry suggests 
emotional connection through narratives as a significant part of development as an adult. After this ending chapter, Barry provides the Do-It-Yourself page that invites readers to create their own autobifictionalography where they summon their own "demons.” Barry recognizes and suggests storytelling and artmaking as key elements in one's development since they allow one to feel connected to others and offer healing. Through her alternative narrative of coming-of age that suggests emotional connection as the development of the narrative, Barry subverts the conventional notions of bildungsroman that Small's memoir seems to follow.

The examination in conventional and alternative models of male and female coming-ofage narrative still requires further investigation after this thesis' production. However, what can be concluded here is that whether traditional or alternative, the two authors of these graphic memoirs, Barry and Small, present their narratives in patterns that allow them to be considered as nonfiction-bildungsroman; the two protagonists, Lynda and David, do achieve optimistic endings that enable us as readers to see them as entering into adulthood, as Trites suggests it (12). Furthermore, because of nonfiction elements in many coming-of-age stories, as Gilmore and Marshall point out when they discussed Small's Stitches (17), make their narratives “crossover" books because they are bildungsroman with actual lived-experiences that frame them as controversial. This is a notable aspect in the ethics of life writing and youth culture. The debate over what knowledge and narrative can be given to children and adolescents certainly does exist, as the heated arguments around censorship persist every year. The controversial aspect of both memoirs of Barry and Small is that the narrative is based on lived-experiences; that they are not fictional. However, as I argue previously, both authors bring fictionality to their accounts, complicating the subjects of truths and lies, and acknowledging the complex ethics of life narrative. The question as to whether these graphic memoirs can be considered as YA 
literature still remains debatable among critics, scholars, and educators since many subjects that Barry and Small deal with may be disturbing subjects of coming-of-age. Yet, the unshakable fact is that these books unquestionably appeal to YA readers since they both deal with the issues of childhood, adolescence, and growing up, specifically traumas of youth that are still not discussed very openly in public or personal spaces today. These narratives are, with no doubt, stories that are crucially necessary to be told, and often silenced voices of trauma that are needed to be heard in our culture in order to enhance our understanding in the subject of trauma and create a space of healing. As these graphic memoirs of childhood trauma cross boundaries between rhetorics, narrations, and readerships (adolescent and adult readers), they provide alternative narrativesthat both adolescent and adult readers can benefit from. Constantly crossing boundaries, Barry and Small present contemporary bildungsroman and an alternative space where adults can recount and look back with the adult narrator, and the adolescent can relate and look forward to the progress with the young protagonists. In result, the process of healing through art-making and dual modes of storytelling is provided for both the author and the audience. 


\section{WORKS CITED}

Abate, Ann Michelle. “Art Spiegelman’s In the Shadow of No Towers as Board Book: From the Matter of Materiality to the Way That Materiality Matters” Jeunesse: Young People, Texts, Cultures, vol. 7, pp. 40-64. https://doi.org/10.1353/jeu.2015.0021. Accessed 3 February 2019.

Adams, Timothy Dow. Telling Lies in Modern American Autobiography. The University of North Carolina Press, 1990

Barry, Lynda. One Hundred Demons. Drawn \& Quarterly, 2017.

Chute, Hillary. Graphic Women: Life Narrative \& Contemporary Comics. Columbia University Press, 2010.

Douglas, Kate. Contesting Childhood: Autobiography, Trauma, and Memory. Rutgers University Press, 2010.

Gilligan, Carol. In a Different Voice: Psychological Theory and Women's Development. Harvard University Press, 1982.

Gilmore, Leigh. The Limits of Autobiography: Trauma and Testimony. Cornell University Press, 2001.

Gilmore, Leigh and Elizabeth Marshall. “Trauma and Young Adult Literature: Representing Adolescence and Knowledge in David Small’s Stitches: A Memoir.” Prose Studies, vol. 35, no.1, 2013, pp.16-38. http://dx.doi.org/10.1080/01440357.2013.781345. Accessed 30 November 2018.

Grattan, Sean. “Affect Studies.” The Bloomsbury Handbook of Literary and Cultural Theory, edited by Jeffrey R. Di Leo, Bloomsbury Academic, 2019. 333-342 
Hirsch, Marianne. Family Frames: Photography Narrative and Postmemory. Harvard University Press, 1997. . “The Generation of Postmemory.” Poetics Today 1 March 2008; 29 (1): 103-128. doi: https://doi.org/10.1215/03335372-2007-019

Hunt, Celia. “Therapeutic Effects of Writing Fictional Autobiography.” Life Writing, vol.7, no.3, pp.231-244. https://www.tandfonline.com/doi/pdf/10.1080/14484528.2010.514142. Accessed 30 November 2018.

Hunt, Nigel C. Memory, War and Trauma. Cambridge University Press, 2010.

Kirtley, Susan E. Lynda Barry: Girlhood Through the Looking Glass. University Press of Mississippi, 2012.

Kois, Dan. “Lynda Barry Will Make You Believe in Yourself.” The New York Times, https://www.nytimes.com/2011/10/30/magazine/cartoonist-lynda-barry-will-make-you-be lieve-in-yourself.html. Accessed 30 November 2018.

Larkin, Ilana. “Absent Eyes, Bodily Trauma, and the Perils of Seeing in David Small’s Stitches.” American Imago: Psychoanalysis and The Human, vol. 71, no. 2, 2014, pp. 183-211. EBSCOhost,libproxy.lib.ilstu.edu/login?url=https://search.ebscohost.com/login.aspx?dire ct=true\&db=mzh\&AN=2014306284\&site=eds-live\&scope=site. Accessed 30 November 2018.

McCloud, Scott. Understanding Comics: The Invisible Art. William Morrow, 1993.

Nodelman, Perry. Words About Pictures: The Narrative Art of Children's Picture Books. The University of Georgia Press, 1988.

Paul, Marla. “Your Memory Is Like the Telephone Game” Northwestern, https://news.northwestern.edu/stories/2012/09/your-memory-is-like-the-telephone-game. Accessed 3 February 2019. 
Pratt, Annis. Archetypal Patterns in Women’s Fiction. Indiana University Press, 1981.

Royle, Nicholas. The Uncanny. Manchester University Press, 2003.

Scarry, Elaine. The Body in Pain: The Making and Unmaking of the World, Oxford University Press, 1985.

Sousanis, Nick. Unflattening. Harvard University Press, 2015.

Small, David. Stitches. W.W. Norton \& Company, 2009.

Smith, Sidonie and Julia Watson. Reading Autobiography: A Guide for Interpreting Life Narratives. University of Minnesota Press, 2010.

Trites, Roberta Seelinger. Disturbing the Universe: Power and Repression in Adolescent Literature. University of Iowa Press, 2000. 